\title{
Los convenios de interés público y de asociación en el régimen de contratación pública colombiana***
}

\section{Public interest and association agreements in the Colombian public procurement system}

RESUMEN

El presente artículo tiene como objeto analizar el régimen jurídico creado con la expedición del Decreto 092 de 2017. Para ello, se recurre a la dogmática jurídica, con el fin de ofrecer un análisis sistemático del régimen en cuestión, acudiendo a fuentes normativas, jurisprudenciales y doctrinales. A partir del análisis, se sostiene que esta nueva regulación distingue entre los convenios de asociación, establecidos en la Ley 489 de 1998 y reglamentados por una parte del mencionado decreto, y los denominados convenios de "interés público" que están previstos en el artículo 355 constitucional. En cuanto a las principales similitudes entre ambas figuras valga destacar que: (i) ambos convenios deben celebrarse con personas jurídicas privadas sin ánimo de lucro y de reconocida idoneidad, (ii) no pueden implicar una relación conmutativa entre las partes, (iii) están sometidos al régimen de inhabilidades e incompatibilidades del Estatuto General de Contratación de la Administración Pública, (iv) les aplican los principios de la contratación estatal y (v) están sujetos a las normas generales aplicables a la contratación pública excepto en lo reglamentado en el Decreto 092 de 2017. El presente artículo realiza un estudio de estos dos tipos de convenios previstos en el

Doctorando en Derecho en la Universidad Pompeu Fabra (Barcelona, España). Profesor e investigador de tiempo completo de la Escuela de Derecho de la Universidad EAFIT (Medellín, Colombia). Contacto: agomezv1@eafit.edu.co

ORCID ID: 0000-0002-6354-5708.

** Magíster en Derecho de la Universidad de Antioquia (Medellín, Colombia). Profesor e investigador de tiempo completo de la Escuela de Derecho de la Universidad EAfIT (Medellín, Colombia).Contacto: cdiazdi@eafit.edu.co ORCID ID: 0000-0001-9139-6941.

**** Recibido el 8 de enero de 2018, aprobado el 11 de junio de 2019.

Para citar el artículo: Gómez Velásquez, A. y Díaz Díez, C. A. Los convenios de interés público y de asociación en el régimen de contratación pública colombiana. En Revista Derecho del Estado, Universidad Externado de Colombia. N. . 44, septiembre-diciembre 2019, pp. 285-325. DOI: https://doi.org/10.18601/01229893.n44.11 
régimen de contratación pública con el fin de explicitar su definición, características, similitudes, diferencias y algunos problemas a los que ha dado lugar su celebración.

PALABRAS CLAVE

Contratación pública, convenios de interés público, convenios de asociación, contrato estatal, contratos de interés público, donaciones públicas, auxilios públicos, entidades privadas sin ánimo de lucro.

\section{ABSTRACT}

The following paper aims to analyze the legal framework of public procurement created with the expedition of Decree 092 of 2017. Through legal research methods, the paper proposes a systematic analysis of the legal framework recurring to normative, jurisprudence and doctrinal sources. Doing so, this paper will be focus on the definitions, typologies, main features and some problematic issues that the regulation implies. It will be held that this new regulation distinguishes between association public agreements, regulated by Act 489 of 1998 and partly by the mentioned decree, and "public interest" agreements that are supported by article 355 of the Colombian Constitution. About the similarities among both agreements it could be established that, (i) both public contracts must be sign up with nonprofit organization with recognized suitability, (ii) neither can imply a commutative relationship, (iii) both are regulated by the regime of disabilities and incompatibilities provided by Act 80 of 1993, (iv) the legal and constitutional principles of public procurement are applicable to them, and (v) both of them are subjects of the general norms applicable to public procurement except on the precise content of Decree 092 of 2017.

\section{KEYWORDS}

Public Procurement, Public Interest Agreements, Association Agreements, Public Contracts, Public Interest Contracts, Public Grants, Nonprofit Organizations.

SUMARIO

Introducción. 1. Las acepciones de "contrato" y "convenio" en la contratación pública colombiana. 2. La problemática distinción de los convenios de asociación respecto de otros convenios en la contratación pública. 3. El convenio de interés público. 3.1. Concepto y fundamento constitucional. 3.2. Antecedentes de la figura del convenio de interés público consagrado 
en el segundo inciso del artículo 355 de la Constitución y su regulación en el Decreto 777 de 1992.3.3. Características del convenio de interés público en la reglamentación contenida en el Decreto 092 de 2017.3.3.1. La regulación de estos convenios es una potestad del Gobierno Nacional, pero que no es exclusiva. 3.3.2. El objeto del convenio de interés público es restringido. 3.3.3. El convenio no puede comportar una relación conmutativa. 3.3.4. Las entidades privadas con las que se pretenda celebrar el convenio deben ser sin ánimo de lucro y de reconocida idoneidad, para lo cual se deben observar los procedimientos y demás requisitos previstos en el Decreto 092 de 2017. 3.3.5. Su celebración requiere de autorización previa, por parte del representante legal de la entidad estatal. 3.3.6. A estos convenios les resultan aplicables tanto el régimen de prohibiciones, inhabilidades e incompatibilidades como los principios de la contratación estatal.3.3.7. Se rigen por las normas especiales del artículo 355 de la Constitución, el Decreto 092 de 2017 y, subsidiariamente, por las normas del EGCAP. 4. El convenio de asociación. 4.1. Concepto y fundamento normativo. 4.2. Características del convenio de asociación previsto en el artículo 96 de la Ley 489 de 1998. 4.2.1. El convenio de asociación puede celebrarse por cualquier entidad estatal.4.2.2. El contratista deberá ser igualmente una entidad particular sin ánimo de lucro y de reconocida idoneidad. 4.2.3. El objeto del convenio de asociación es el desarrollo de cometidos y/o funciones públicas propias de las entidades estatales. 4.2.4. No puede haber remuneración sino aportes de los asociados. 4.2.5. La selección de la entidad sin ánimo de lucro y de reconocida idoneidad debe hacerse por proceso competitivo como regla general. 4.2.6. Le aplican las prohibiciones, inhabilidades e incompatibilidades de la contratación estatal. 4.2.7. Les aplican los principios de la contratación estatal y algunas normas presupuestales. 4.2.8. Deben observar las normas generales del sistema de contratación pública. Conclusiones. Referencias.

\section{INTRODUCCIÓN}

En la Asamblea Nacional Constituyente de 1991 hubo consenso en torno a la necesidad de impedir que el giro de recursos económicos por parte del Estado a particulares dependiera del vaivén de las fuerzas políticas y que pudiera derivar en el fomento del clientelismo y la corrupción. En este sentido, se aprobó la prohibición para todas las ramas u órganos del poder público, contenida en el artículo 355 constitucional, de decretar auxilios o donaciones en favor de personas naturales o jurídicas de derecho privado. Con esta medida, el constituyente pretendió poner fin a los conocidos fenómenos de corrupción y de clientelismo que se asociaban a los tristemente célebres "auxilios parlamentarios".

Sin embargo, dicha prohibición constitucional no implicó que se proscribiera cualquier forma de colaboración o cooperación entre Estado y particulares en 
el desarrollo de fines y programas públicos. Precisamente, a este objetivo se dirige el parágrafo segundo del mencionado artículo constitucional que regula una forma particular de relacionamiento entre el Gobierno, en sus distintos niveles territoriales, y entidades particulares sin ánimo de lucro. En virtud del mencionado mandato constitucional, este tipo de colaboración se materializa en el contrato que puede celebrarse entre ambas partes, con recursos de los respectivos presupuestos públicos, siempre y cuando su finalidad sea la de impulsar programas y actividades de interés público de acuerdo con los planes de desarrollo correspondientes.

En lo que concierne a la competencia para regular esta figura contractual y a pesar de la pretensión del constituyente de abolir los reglamentos autónomos constitucionales, esta se sustrajo de la órbita del Congreso de la República como una garantía adicional para evitar la tentación de los miembros de la rama legislativa de reincidir en las conductas antes referidas. Por lo tanto, la potestad de reglamentación se radicó en cabeza del Gobierno Nacional. Haciendo uso de esta competencia, el Gobierno expidió inicialmente los decretos 777 de 1992, 1403 de 1992 y 2459 de 1993. Tras cerca de 25 años de vigencia, varios proyectos de reforma, y a raíz de reiteradas críticas referidas a la falta de claridad, coherencia y completitud del régimen creado, sumado a la evidencia de fenómenos de corrupción presentados con motivo de la aplicación de dicha figura contractual, a comienzos de 2017 se decidió expedir una nueva regulación.

En este contexto, el presidente Juan Manuel Santos expidió el Decreto 092 de 2017, no sin antes afirmar que con este se pretendía hacer frente a un régimen que estaba "fuera de control"1, por el cual se estaba "colando buena parte de la corrupción del país" ${ }^{2}$ y que se había convertido en la "herramienta

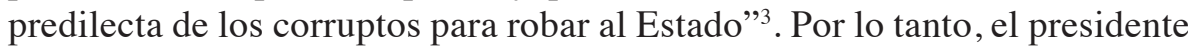
incluyó la expedición de la nueva normatividad dentro de un conjunto de medidas administrativas, legislativas y de política pública dirigidas a la lucha contra la corrupción en el país. Al descender al reglamento mencionado, dicha intención es evidente desde los considerandos y a lo largo de la regulación creada. Incluso, la distinción que en ella se hace entre los contratos que se suscriben con fundamento en el artículo 355 constitucional y los convenios de asociación debería poder explicarse siguiendo esa lógica.

Teniendo en cuenta que ha pasado un tiempo prudente desde la expedición del mencionado decreto y que los tipos contractuales allí regulados resultan

1 Declaración del Presidente Juan Manuel Santos en la firma del Decreto 092. En Sala de Prensa, Colombia Compra Eficiente. 23 de enero de 2017. [En línea]. Disponible en: https:// www.colombiacompra.gov.co/sala-de-prensa/videos/declaracion-del-presidente-juan-manuelsantos-en-la-firma-del-decreto-092 [Consultado el 10 de abril de 2019].

2 Ibíd.

3 Ibíd. 
valiosos y necesarios para generar sinergias entre el sector público y el privado para el desarrollo de fines estatales, este artículo tiene como principal objetivo presentar una propuesta de interpretación sistemática del régimen creado por el Decreto 092 de 2017, concentrándose para ello en la distinción que se propone entre los convenios que se denominarán de interés público y los de asociación. En este sentido, el artículo constituye un ejercicio de dogmática jurídica, de lege lata, con pretensiones tanto descriptivas como propositivas respecto del régimen jurídico aplicable a los mencionados convenios. Con ese fin, se recurre a fuentes legales, jurisprudenciales y doctrinales, para dar sustento a la posición asumida, en especial respecto de las diferencias y similitudes entre los mencionados convenios.

El artículo se estructura en cuatro apartados. En el primero de ellos se analizan las acepciones de "contrato" y "convenio" en la contratación pública colombiana. En el segundo, se aborda la problemática distinción de los convenios de asociación respecto de otras figuras en la contratación pública. En el tercero y el cuarto, se estudian los convenios de interés público y de asociación, respectivamente. Para cada uno de ellos se expone su concepto, fundamento constitucional, antecedentes normativos y características a la luz de la normativa vigente. En el apartado de conclusiones se ofrece una síntesis de las diferencias y similitudes identificadas entre los mencionados convenios.

\section{LAS ACEPCIONES DE "CONTRATO" Y “CONVENIO" EN LA CONTRATACIÓN PÚBLICA COLOMBIANA}

Ha hecho carrera en la práctica de la contratación pública colombiana la idea de que los convenios y los contratos son conceptos diferentes. Este planteamiento se ha sustentado por algunos con el argumento de que, mientras los contratos estatales se caracterizan por ser acuerdos de voluntades generadores de obligaciones, es decir, que originan contraprestaciones en dinero o en especie, los convenios son acuerdos de colaboración o de cooperación mutua en los cuales no está presente el rasgo de la contraprestación y, en tal sentido, no dan lugar a la obligación de pagar por la prestación de un servicio, la ejecución de una obra o el suministro de un bien o servicio ${ }^{4}$.

Sin embargo, no se observa un fundamento normativo claro para sostener que los convenios y contratos estatales sean figuras distintas, ni desde el

4 Dicha postura ha gozado, incluso, de aceptación doctrinaria, sobre todo a partir de la obra de Augusto Ramón Chávez Marín, quien propone distinguir el contrato administrativo (o estatal, según la terminología empleada por el Estatuto General de Contratación de la Administración Pública, EGCAP), del convenio de la Administración, afirmando que, mientras en los contratos existe contraposición de intereses (es decir, contraprestaciones), en los convenios la misma está ausente, ya que estos se fundan en relaciones de cooperación o de colaboración recíproca. Chávez MARín, A. R. Los convenios de la Administración. Entre la gestión pública y la actividad contractual. 3. ${ }^{\text {a }}$ ed. Bogotá: Temis, 2015, 1-3, 57. 
punto de vista formal ni desde el sustancial, porque en nuestro ordenamiento jurídico el contrato o convención se define como "un acto por el cual una parte se obliga para con otra a dar, hacer o no hacer alguna cosa" ${ }^{\prime}$, independientemente del contenido o finalidad que lo inspira. Además, el artículo 32 de la Ley 80 de 1993 dispone que "[s]on contratos estatales todos los actos jurídicos generadores de obligaciones que celebren las entidades a que se refiere el presente estatuto, previstos en el derecho privado o en disposiciones especiales, o derivados del ejercicio de la autonomía de la voluntad, así como los que, a título enunciativo, se definen" en dicha norma. Incluso, desde un punto de vista lingüístico, la palabra "convenio" se define como "[a]cuerdo o pacto" $"$, lo que resulta acorde con la conceptualización del contrato como acuerdo de voluntades o como pacto entre varios sujetos para obligarse; circunstancia que se presenta en los convenios, con independencia de su contenido o finalidad, pues allí también surgen obligaciones de dar, hacer o no hacer. En tal sentido, más que expresiones diferentes o enmarcadas en una relación de género a especie, las palabras "contrato" y "convenio" son sinónimas.

Según se indicó, dentro de la doctrina nacional, el completo estudio que realiza Augusto Ramón Chávez Marín sugiere diferenciar los contratos administrativos de los convenios de la administración -categoría esta última que incluye los convenios administrativos, así como los interadministrativos- a partir de la causa de su celebración. Afirma este autor que si bien en el ordenamiento jurídico colombiano los convenios de la administración se han tratado como una expresión del contrato administrativo (o estatal), puede decirse que en los últimos tiempos aquellos han ido cobrando autonomía ${ }^{7}$. De ahí que, para Chávez, "los convenios de la administración constituyen una categoría jurídica distinta del contrato administrativo o estatal"8. Sin embargo, más adelante dicho autor admite que los convenios de la administración son una manifestación de la actividad contractual del Estado, planteando incluso que "se debe comenzar por la revisión de la teoría del contrato administrativo y de los elementos relevantes de la discusión que implica, para afirmar posteriormente la pertenencia del convenio de la administración a esa categoría jurídica"9.

No obstante, Chávez propone un concepto restringido de contrato, a partir del criterio de la causa o finalidad que motiva la celebración del negocio. En tal sentido, expresa que,

$5 \quad$ Art. 1495 del Código Civil.

6 Real Academia Española de la Lengua. Diccionario de la lengua española. Disponible en: http://dle.rae.es/?id=AgBNpjI

7 Chávez Marín. Los convenios de la Administración, cit., 3-7.

8 Ibíd., 9.

9 Ibíd., 15. 
... atendiendo a la causa que conduce a producir la manifestación, es decir, a celebrar el negocio correspondiente, o al observar el fin que guía la declaración de voluntad, se puede distinguir la existencia de dos tipos de actos jurídicos, vale decir, distintos: unos para los que resulta conveniente y procedente mantener la denominación de contrato y otros negocios para los que es procedente bautizarlos o nominarlos como convenios ${ }^{10}$.

Como se observa, se trata de una propuesta doctrinaria (de lege ferenda), y no de una conclusión dogmática de carácter descriptivo (de lege lata), pues los artículos 1495 del Código Civil y 32 de la Ley 80 de 1993 no distinguen los contratos y los convenios, según la causa de su celebración.

Además, esta propuesta de distinción entre el contrato y el convenio es problemática, pues genera dificultades para su entendimiento. Como se dijo previamente, si bien Chávez sostiene, como planteamiento principal, que los convenios son un género distinto al de los contratos, en otros acápites de su libro expresa que los convenios son una manifestación de la actividad contractual y que, en tal medida, son una especie del contrato ${ }^{11}$, lo que causa perplejidad. Dicha dificultad pretende eliminarla con la explicación que más adelante realiza, según la cual el convenio solo puede considerarse una especie del contrato desde una perspectiva formal o voluntarista -por ser, como este, un acuerdo de voluntades, del que emanan obligaciones-, pero no desde una perspectiva causal, finalista o sustancial, pues desde este punto de vista son dos géneros distintos, ya que, mientras en el contrato hay contraposición de intereses, en el convenio hay unidad de causa o finalidad (de ayuda, cooperación, coordinación o apoyo, a partir de intereses comunes) $)^{12}$. De donde se concluye, por tanto, que para dicho autor el convenio es un contrato solo formalmente, no sustancialmente. He ahí la dificultad de este criterio de distinción. Además, ¿qué implicaciones jurídicas relevantes se generan en la práctica por el hecho de sostener la distinción sustancial entre contratos y convenios administrativos si, como admite el mismo autor, al ser homologables formalmente, se les deben aplicar las mismas disposiciones ${ }^{13}$. Debido a lo anterior, existen argumentos normativos y conceptuales para afirmar que todo convenio es un contrato, y que si aquel se celebra por una entidad estatal, es un contrato estatal, toda vez que el régimen de contratación

10 Ibíd., 49-50.

11 Ibíd., 15. Al respecto, véase también la nota 3 de la p. 18, en la que acepta que los convenios de la Administración son, ante todo, contratos.

12 Ibíd., 51. Una posición similar sostiene Jorge Enrique Santos al afirmar que "la diferencia entre contrato y convenio de la administración salta a la vista: en el primero, los intereses y finalidades de las partes pueden verse como opuestos, en tanto que, en el segundo, las necesidades que se pretende satisfacer por las partes son idénticas y coinciden con el interés general". SANTOS RODRÍGUEZ, J.E. Consideración sobre los contratos y convenios interadministrativos. En Revista digital de Derecho Administrativo, Universidad Externado de Colombia. N. o 1, 2009, 6.

13 Ibíd., 54. 
pública acoge un criterio orgánico o subjetivo para la definición del contrato estatal, esto es, lo entiende como aquel celebrado entre dos o más entidades públicas, o entre estas y los particulares ${ }^{14}$.

Es cierto que en la regulación actual de los convenios estatales -como se verá en apartados posteriores de este escrito- tanto el constituyente como el legislador y el Gobierno Nacional han otorgado a algunos de aquellos determinados rasgos peculiares, como el impulso de tareas de interés público o la cooperación en el cumplimiento de funciones administrativas, pero esto no se opone a llamar convenios también a los demás contratos estatales, como verdaderas convenciones que son, según el artículo 1495 del Código Civil. Lo que sucede es que, en el ámbito del derecho público, no todas las convenciones pueden versar sobre las mismas materias. Dicho de otra manera, el ordenamiento jurídico en algunos casos restringe la autonomía de la voluntad de las entidades públicas para convenir, exigiendo el cumplimiento de ciertos requisitos. Es esto lo que sucede con los convenios previstos en el artículo 355 de la Constitución -que el mismo constituyente denomina contratos ${ }^{15}-\mathrm{y}$ en el artículo 96 de la Ley 489 de 1998, en los que no se permite el pago, como contraprestación directa por la ejecución de las actividades a cargo de cada una de las partes; pero esto no significa que no sean contratos, tal como se señaló en párrafos precedentes. Teniendo en cuenta estas precisiones terminológicas, a continuación se realizará un estudio de dos de los tipos de convenios previstos en el régimen de contratación pública, con el fin de explicitar su definición, sus características y algunos problemas a los que ha dado lugar su celebración.

\section{LA PROBLEMÁTICA DISTINCIÓN DE LOS CONVENIOS DE ASOCIACIÓN RESPECTO DE OTROS CONVENIOS EN LA CONTRATACIÓN PÚBLICA}

Durante la vigencia del Decreto 777 de $1992^{[16]}$ se presentó la discusión de si la modalidad contractual prevista en el artículo 96 de la Ley 489 de 1998,

14 Véase art. 2. ${ }^{\circ}$ de la Ley 80 de 1993. Este criterio ha sido reiterado por la jurisprudencia administrativa. Al respecto véase, entre otros, Consejo de Estado, Sala de lo Contencioso Administrativo, Sección Tercera, Subsección A. Sentencia del 13 de agosto de 2014. C.P.: Carlos Alberto Zambrano Barrera. Actor: Gloria Lyda Rengifo Alarcón. Demandado: Municipio de Palmira y otros. Rad. 76001-23-31-000-2000-01885-01 (26765).

15 El segundo inciso del artículo 355 de la Constitución Política permite al Gobierno, en los distintos niveles, celebrar "contratos" para impulsar programas o actividades de interés público acordes con los planes de desarrollo; contratos a los que la doctrina ha denominado "convenios de interés público"; una muestra más de la sinonimia entre los conceptos de contrato y convenio. Así lo reconoció Colombia Compra Eficiente al indicar que "[e]l artículo 355 de la Constitución determina que el instrumento que contiene el mecanismo de cooperación del Gobierno y la ESAL es el contrato sin especificar una tipología”. Colombia Compra Eficiente. Guía para la contratación con entidades privadas sin ánimo de lucro y de reconocida idoneidad G-GESAL-03, 10.

16 Decreto 777 de 1992, "Por el cual se reglamenta la celebración de los contratos a que refiere el inciso segundo del artículo 355 de la Constitución Política", del 16 de mayo de 1992. Este decreto fue reformado por los decretos 1403 de 1992 y 2459 de 1993. 
en sus dos primeros incisos, era diferente de la consagrada en el artículo 355 constitucional y regulada por el mencionado decreto. La discusión es importante, ya que los términos en que se regulan ambos contratos son distintos, a pesar de que el artículo 96 de la Ley 489 de 1998 señala que dicha modalidad contractual debe celebrarse "de conformidad con lo dispuesto en el artículo 355 de la Constitución Política" ${ }^{17}$.

$\mathrm{Al}$ respecto, la jurisprudencia, tanto constitucional ${ }^{18}$ como administrati$\mathrm{va}^{19}$, además de una parte de la doctrina especializada ${ }^{20}$, había interpretado sistemáticamente ambas disposiciones afirmando que los condicionamientos constitucionales también debían exigirse de la modalidad contractual del artículo 96 de la Ley 489 de 1998, atendiendo al criterio de jerarquía normativa. En este sentido, no solo las condiciones del artículo 355 constitucional, sino también las de su reglamentación en el Decreto 777 de 1992, debían serles aplicables, toda vez que la figura prevista en el artículo 96 de la citada ley debía entenderse como una mera reiteración de la institución constitucional ya existente, es decir, la del convenio consagrado en el artículo 355 superior. Por su parte, alguna parte de la doctrina ${ }^{21} \mathrm{y}$ ciertas entidades estatales optaron por establecer la posibilidad de diferenciar ambos tipos contractuales ${ }^{22}$.

17 Ley 489 de 1998, "Por la cual se dictan normas sobre la organización y funcionamiento de las entidades del orden nacional, se expiden las disposiciones, principios y reglas generales para el ejercicio de las atribuciones previstas en los numerales 15 y 16 del artículo 189 de la Constitución Política y se dictan otras disposiciones", del 29 de diciembre de 1998. Diario Oficial n. ${ }^{\circ} 43464$.

18 Corte Constitucional, Sala Plena. Sentencia C-671 de 1999. M.P.: Alfredo Beltrán Sierra.

19 Consejo de Estado, Sala de lo Contencioso Administrativo, Sección Tercera. Sentencia del 3 de diciembre de 2014. C.P.: Olga Mélida Valle de la Hoz. Rad.51832, y Consejo de Estado, Sala de Consulta y Servicio Civil. Concepto 2146 del 12 de septiembre de 2013. C.P.: William Zambrano Cetina; entre otros.

20 Chávez Marín. Los convenios de la Administración, cit., 370; Pachón Lucas, C. Contratación pública. Análisis normativo, descripción de procedimientos. Bogotá: ECOE, 2014; FonseCa Gómez, O. J. Los convenios de asociación. Una mirada desde el estatuto contractual y el Distrito Capital. Tesis de maestría en Derecho. Bogotá: Universidad Nacional de Colombia, $2012,51$.

21 En este sentido se pronuncia Víctor A. Naranjo al sostener: "De lo anterior surge la validez de la diferenciación que hace un sector de la doctrina respecto a los convenios inspirados en el artículo 355 de la Constitución Política y los emanados del artículo 96 de la ley 489 de 1998; los primeros serían aquellos en que la administración pública transfiere los recursos públicos para que un objeto misional de la organización sin ánimo de lucro, que coincide con los objetivos de la entidad pública, se lleve a cabo; y los segundos son aquellos convenios en donde la entidad pública celebra un acuerdo de voluntades con los particulares para desarrollar uno de sus objetivo institucionales y el cual comparte con este". NARANJo CELY, V. A. Los convenios de asociación e interés público, entre el ejercicio del poder discrecional de la Administración y la aplicación de los principios de la contratación estatal en Colombia. Tesis de maestría en Derecho. Bogotá: Universidad Nacional de Colombia, 2014, 69.

22 Alcaldía Mayor de Bogotá. Decreto Distrital n. 153 de 2010; Gobernación de Antioquia. Circular n. ${ }^{\circ} 000386$ del 19 de septiembre de 2012; Alcaldía de Medellín. Decreto Municipal n. ${ }^{\circ}$ 
Para ello, se partía del argumento de mantener el efecto útil del mencionado artículo 96, diferenciando principalmente los fines que debían buscar cada uno de los tipos contractuales, atendiendo al tenor literal de las disposiciones en cuestión.

A pesar de la contundencia de la argumentación sostenida por la primera posición y su reiteración por parte de la jurisprudencia, recientemente se ha saldado dicha discusión con la expedición del Decreto 092 de 2017 por parte del Gobierno Nacional, con fundamento en la competencia otorgada por el artículo 355 de la Constitución, derogándose el Decreto 777 de 1992 y demás normas concordantes. El artículo $5^{\circ}$, inciso final, del nuevo decreto dispone que "[e]stos Convenios de Asociación son distintos a los contratos a los que hace referencia el artículo 2 y están regidos por el artículo 96 de la Ley 489 de 1998 y los artículos 5, 6, 7 y 8 del presente decreto" ${ }^{\text {23. Por lo }}$ tanto, a partir de la regulación especial expedida por el Gobierno Nacional, deben diferenciarse desde el $1 .^{\circ}$ de junio de 2017 los llamados convenios de interés público ${ }^{24}$, previstos en el artículo 355 constitucional y regulados en su integridad por el Decreto 092 de 2017, y los convenios de asociación ${ }^{25}$, consagrados en el artículo 96 de la Ley 489 de 1998 y regulados exclusivamente en los artículos 5, 6, 7 y 8 del Decreto 092 de 2017.

La naturaleza jurídica de este decreto ha dado lugar a la discusión acerca de si se trata de un decreto autónomo (constitucional) o de un decreto reglamentario de la ley. Al respecto, puede afirmarse que tiene una naturaleza dual: 1. Por un lado, es un decreto autónomo o constitucional, en lo que atañe a la regulación de los convenios de interés público, es decir, al desarrollo, por parte del Gobierno Nacional, de lo dispuesto en el artículo 355 superior; pues en este caso ha sido directamente el constituyente quien ha otorgado al Gobierno la competencia para regular dicho tópico constitucional ${ }^{26}$, razón por

1920 del 1. ${ }^{\circ}$ de diciembre de 2015. Sobre las implicaciones de esta diferencia en la contratación del Distrito Capital véase Fonseca Gómez. Los convenios de asociación, cit., 49 ss.

23 Decreto 092 de 2017 del Departamento Nacional de Planeación, "Por medio del cual se reglamenta la contratación con entidades privadas sin ánimo de lucro a la que hace referencia el inciso segundo del artículo 355 de la Constitución Política", del 23 de enero de 2017.

24 Según Rodríguez Tamayo, "[e]l contrato de interés público se define como el negocio jurídico que celebra una entidad estatal con una ESAL que cuenta con una acreditada y suficiente idoneidad, con el propósito principal de ejecutar un programa o una actividad de interés público, en el marco del plan de desarrollo respectivo". RodríGuez Tamayo, M. Contratación pública con entidades sin ánimo de lucro. Decreto 092 de 2017. Bogotá: Legis, 2017, 77.

25 En palabras de Chávez Marín, los convenios de asociación "constituyen un vínculo de carácter temporal entre la administración y personas jurídicas particulares que tiende a realizar objetivos comunes a ambas partes. En este caso la actividad la desarrollan ambas partes, conjunta y coordinadamente: administración y particulares. En tal sentido opera una verdadera asociación de personas, una conjunción de esfuerzos”. Chávez Marín. Los convenios de la Administración, cit., 369 .

26 Esta idea es compartida por Chávez Marín. Los convenios de la Administración, cit., 377 . 
la cual no constituye ejercicio de una potestad administrativa supeditada a la existencia de norma legal previa, sino, en palabras del Consejo de Estado, una norma "sui generis, de naturaleza constitucional, por ende, su jerarquía normativa no resulta inferior a la de la ley" ${ }^{27} ; 2$. Por otra parte, en tanto algunas disposiciones del mencionado decreto (arts. 5..$^{\circ}$ a $8 .^{\circ}$ ) reglamentan, a su vez, el denominado convenio de asociación, creado por el artículo 96 de la Ley 489 de 1998, estas corresponden en rigor al ejercicio de la potestad reglamentaria ordinaria (secundum legem) que ostenta el Presidente de la República en virtud del artículo 189, numeral 11, constitucional, y, por tanto, su naturaleza jurídica es la de un decreto reglamentario, que se encuentra supeditado a la norma legal ya mencionada. Esta naturaleza mixta hace complejo el análisis de la amplitud de las competencias otorgadas al Gobierno Nacional y del control que debe realizarse sobre las mismas. Atendiendo a la diferenciación hecha entre convenios de interés público y convenios de asociación, se abordan a continuación ambas tipologías contractuales.

\section{EL CONVENIO DE INTERÉS PÚBLICO}

\subsection{Concepto y fundamento constitucional}

Dentro de la clasificación que suele hacerse de los convenios que pueden celebrar las entidades estatales y los particulares, encuentra fundamento el consagrado en el artículo 355 de la Constitución Política.

De su contenido se advierte que el primer inciso de la norma prevé una prohibición -aunque no absoluta- de decretar auxilios o donaciones a favor de personas de derecho privado, es decir, de pactar prestaciones a cargo del Estado y en beneficio de los particulares, fundadas en la mera liberalidad ${ }^{28}$, y a las que tradicionalmente se les denominó "auxilios parlamentarios" 29 . Por otra parte, el convenio al que se refiere el segundo inciso de la norma es aquel que las entidades públicas, en los correspondientes niveles del Gobierno ${ }^{30}$,

27 Consejo de Estado, Sala de lo Contencioso Administrativo, Sección Tercera. Sentencia del 5 de julio de 2017. C.P.: Jaime Orlando Santofimio Gamboa. Actor: Julián Andrés Cotes Buitrago y otros. Demandado: Departamento Nacional de Planeación. Rad. 111001-03-26-0002017-00083-00 (59493).

28 Sentencia C-372 de 1994. M.P.: Vladimiro Naranjo Mesa.

29 La doctrina ha destacado que el artículo 355 de la Constitución Política se redactó con la intención de abolir los auxilios parlamentarios. CHÁvez MaRín. Los convenios de la Administración, cit., 374-375. Así también lo reconoce la Guía para la contratación con entidades privadas sin ánimo de lucro y de reconocida idoneidad G-GESAL-03, expedida por la Agencia de Contratación Pública Colombia Compra Eficiente, 4.

30 Este concepto resulta problemático. En efecto, el artículo 355 de la Constitución autoriza al Gobierno, en los niveles nacional, departamental, distrital y municipal, a celebrar estos convenios. Ahora bien, una noción restrictiva de Gobierno es aquella que considera que a nivel nacional hace alusión al Presidente de la República y a su correspondiente ministro o director 
pueden celebrar con entidades sin ánimo de lucro y de reconocida idoneidad para impulsar programas y actividades que guarden relación con el Plan Nacional o los planes seccionales de desarrollo. Por tal razón, a estos acuerdos jurídicos podría denominárseles - para distinguirlos de los regulados en el artículo 96 de la Ley 489 de 1998- convenios de interés público ${ }^{31}$. A través de estos convenios se permite que el Estado continúe participando, junto al sector privado, de la ejecución de proyectos de interés general que no impliquen contraprestaciones económicas para las partes, sino el desarrollo de tareas conjuntas, en procura de la satisfacción de las necesidades colectivas ${ }^{32}$, asumiéndose esta participación pública como una "acción benéfica" ${ }^{33}$ del Estado. Por tal razón, la Corte Constitucional ha considerado que la celebración de estos convenios para impulsar programas y actividades de interés público acordes con los planes nacional y seccionales de desarrollo constituye una excepción a la prohibición de decretar auxilios y donaciones a favor de los

de departamento administrativo, y a nivel departamental, distrital o municipal, al gobernador o alcalde, respectivamente, junto con su secretario de despacho o director de departamento administrativo. Sin embargo, no ha sido esta la interpretación acogida por la Agencia de Contratación Pública Colombia Compra Eficiente, ni por la doctrina autorizada en la materia, pues lo que se ha sostenido es que el concepto de Gobierno previsto en el segundo inciso de la norma constitucional en comento debe entenderse como el conjunto de órganos de la rama ejecutiva del poder público, quedando por fuera de dicho término las entidades que pertenezcan a otras ramas, así como los órganos constitucionales autónomos, los cuales, por tanto, no pueden celebrar los convenios de interés público a los que se refiere el mencionado artículo 355 constitucional (véase Colombia Compra Eficiente. Guía, cit., p. 7; Chávez MaRín. Los convenios de la Administración, cit., 377). Sin embargo, Colombia Compra Eficiente se contradice en su Circular Externa Única, cuando afirma que las entidades estatales, pertenecientes a la Rama Ejecutiva, que cuenten con un régimen legal especial en materia contractual, "no podrán celebrar contratos de interés público a los que se refiere el artículo 2 del Decreto 092 de 2017 por cuanto no son parte del Gobierno nacional, departamental, distrital ni municipal". Colombia Compra Eficiente, Circular Externa Única, cit., 67. Si en la Guía esta agencia había sostenido que el concepto de Gobierno incluye a todos los órganos del sector central y descentralizado por servicios, de todos los niveles de la rama ejecutiva, no se comprende por qué en la Circular excluye a los que tienen un régimen contractual especial.

31 Denominación compartida por CHÁvEZ MaRín. Los convenios de la Administración, cit., 373. La Agencia de Contratación Pública Colombia Compra Eficiente los llama "contratos de interés público o de colaboración". Colombia Compra Eficiente. Guía, cit., 7. Nombre que también utiliza Rodríguez Tamayo. Contratación pública con entidades sin ánimo de lucro, cit., 1.

32 Véase sentencia C-372 de 1994, M.P.: Vladimiro Naranjo Mesa. En la misma línea, véanse las sentencias C-506 de 1994. M.P.: Fabio Morón Díaz, C-205 de 1995. M.P.: Eduardo Cifuentes Muñoz, C-254 de 1996. M.P.: Eduardo Cifuentes Muñoz, C-152 de 1999. M.P.: Eduardo Cifuentes Muñoz, C-922 de 2000 . M.P.: Antonio Barrera Carbonell, C-651 de 2001 . M.P.: Alfredo Beltrán Sierra, C-1168 de 2001. M.P.: Eduardo Montealegre Lynett, C-1174 de 2001. M.P.: Clara Inés Vargas Hernández, C-1250 de 2001. M.P.: Manuel José Cepeda Espinosa, C-712 de 2002. M.P.: Álvaro Tafur Galvis, C-130 de 2003. M.P.: Rodrigo Escobar Gil), C-022 de 2004. M.P.: Alfredo Beltrán Sierra, C-507 de 2008. M.P.: Jaime Córdoba Triviño, C-324 de 2009. M.P.: Juan Carlos Henao Pérez, C-044 de 2015. M.P.: María Victoria Calle Correa) y C-027 de 2016. M.P.: María Victoria Calle Correa.

33 Corte Constitucional, Sala Plena. Sentencia C-543 de 2001. M.P.: Álvaro Tafur Galvis. 
particulares; es decir que admite que en este caso también el Estado estaría otorgando auxilios, pero que resultan ajustados a la Constitución ${ }^{34}$.

Ahora bien, como se indicó en el numeral 2 del presente texto, existe discusión acerca de si a esta modalidad de convenio puede denominársele o no "convenio de asociación". En vigencia del Decreto 777 de 1992, la Sección Tercera del Consejo de Estado tomó partido por una tesis afirmativa, al considerar que el convenio previsto en el artículo 96 de la Ley 489 de 1998 -al que el legislador le otorga el nombre de convenio de asociación- no es más que el desarrollo de la figura contractual prevista en el artículo 355 de la Constitución y que además debe cumplir con los preceptos del Decreto 777 de 1992. Bajo esta premisa, el llamado convenio de interés público se entendió por la jurisprudencia contencioso administrativa como un sinónimo de convenio de asociación ${ }^{35}$. Como se observa, la definición que el Consejo de Estado ha construido de los convenios de asociación contiene los mismos términos del inciso segundo del artículo 355 de la Constitución. En similar sentido, la Corte Constitucional ha reconocido que la institución contractual a la que se refiere el artículo 96 de la Ley 489 de 1998 es un desarrollo de la que prevé el artículo 355 de la Constitución, porque el legislador supedita la primera al cumplimiento de los requisitos establecidos en el mandato superior ${ }^{36}$. En consecuencia, no ha sido clara la diferencia entre los convenios de interés público previstos en la Constitución Política y los de asociación regulados por el legislador; y, por el contrario, al parecer, jurisprudencialmente se les había asimilado, bajo la categoría de los convenios de asociación.

No obstante, como se dijo anteriormente, el Decreto 092 del 23 de enero de 2017 -que entró a regir el 1. . de junio de 2017 y derogó los decretos 777 de 1992,1403 de 1992 y 2459 de 1993 - dispone en su artículo 5..$^{\circ}$, inciso final, que los convenios de asociación a los que hace referencia el artículo 96 de la Ley 489 de 1998 son distintos a los regulados en el artículo 2. ${ }^{\circ}$ del mencionado decreto, es decir, a los que se desprenden del segundo inciso del artículo 355 de la Constitución. Sin embargo, el inciso final del artículo 5 . del Decreto 092 de 2017 incurre en una contradicción, primero, al predicar la distinción entre ambas instituciones contractuales, y luego, al volver a asociarlas, cuando dice que los convenios de asociación estarán regidos por el artículo 96 de la Ley 489 de 1998, norma esta que en su segundo inciso

34 Corte Constitucional, Sala Plena. Sentencia C-044 de 2015. M.P.: María Victoria Calle Correa. Así también lo señaló el Decreto 092 de 2017.

35 Consejo de Estado, Sala de lo Contencioso Administrativo, Sección Tercera, Subsección C. Sentencia del 3 de diciembre de 2014. C.P.: Olga Mélida Valle de De La Hoz. Actor: Asociación Promotora de Proyectos Servicios y Asesoría Culturales Proactiva y otros. Demandado: Bogotá - Distrito Capital - Secretaría Distrital de Integración Social. Rad. 25000-23-36-0002014-00199-01(51832).

36 Corte Constitucional, Sala Plena. Sentencia C-671 de 1999. M.P.: Alfredo Beltrán Sierra. 
establece que "[1]os Convenios de Asociación a que se refiere el presente artículo se celebrarán de conformidad con lo dispuesto en el artículo 355 de la Constitución Política”. Por lo tanto, la nueva regulación de los convenios sigue dando pie al debate acerca de la naturaleza de ambas figuras. La contradicción a la que se alude se hace explícita en lo siguiente: a pesar de que el Decreto 092 de 2017 distingue los convenios de interés público y los de asociación, en últimas, mantiene la exigencia de que ambos respeten el contenido del artículo 355 de la Constitución, resultando, entonces, sustancialmente identificables, no obstante que el trámite de su celebración tenga algunas diferencias.

En suma, se considera que, no obstante que los convenios de interés público que se pueden celebrar para realizar programas acordes con el plan nacional y los planes seccionales de desarrollo con personas sin ánimo de lucro de reconocida idoneidad y los convenios de asociación a los que alude el artículo 96 de la Ley 489 de 1998 tienen una misma fuente constitucional, que establece requisitos conjuntos para su celebración -el artículo 355 de la Carta Política-, se ha expedido una reglamentación que los distingue formalmente.

\subsection{Antecedentes de la figura del convenio de interés público consagrado en el segundo inciso del artículo 355 de la Constitución y su regulación en el Decreto 777 de 1992}

Resulta importante explicar, con miras a una mayor comprensión del sentido y de los condicionamientos a los que está sujeta la celebración de los convenios de interés público en nuestro ordenamiento jurídico, que el primer inciso del artículo 355 de la Constitución se inspiró en el propósito de evitar que los recursos públicos fueran utilizados para otorgar dádivas arbitrarias a los particulares, como ya había sucedido en la historia del país ${ }^{37}$. Atendiendo el mandato dirigido por el constituyente al Gobierno Nacional, de reglamentar la celebración de los contratos a los que se refiere el segundo inciso del artículo 355 de la Constitución, aquel expidió el Decreto 777 del 16 de mayo de 1992, estableciendo, para dichos acuerdos, el cumplimiento de los requisitos y las consecuencias jurídicas que se indican a continuación:

a) Solemnidad, como condición para el perfeccionamiento del contrato, al contemplar la exigencia de que los contratos celebrados con el propósito de impulsar tales programas y actividades de interés público constaran por escrito (art. $1 .^{\circ}$ ).

b) Sujeción de estos contratos al derecho privado, salvo en las materias respecto de las cuales rige el EGCAP -como, p. ej., en la inclusión de cláusulas exorbitantes- $\left(\operatorname{art} .1 .^{\circ}\right)$.

37 Corte Constitucional, Sala Plena. Sentencia C-671 de 1999. M.P.: Alfredo Beltrán Sierra. 
c) Publicación en el Diario Oficial o en los diarios, gacetas o boletines territoriales y aprobación del Consejo de Ministros de ciertas entidades del orden nacional, ambos requisitos solo para los contratos celebrados con determinadas cuantías (art. 1. ${ }^{\circ}$, modificado por el art. 1..$^{\circ}$ del Decreto 1403 de 1992).

d) Motivación por parte de la entidad pública de la reconocida idoneidad de la persona sin ánimo de lucro con la que se pretende celebrar el contrato, a partir de la experiencia, basada en la capacidad técnica y administrativa (art. 1. ${ }^{\circ}$, modificado por el art. 1. ${ }^{\circ}$ del Decreto 1403 de 1992).

e) Proscripción de una contraprestación directa a favor de la entidad pública por parte de la persona sin ánimo de lucro (art. $2 .^{\circ}$ ).

f) Autorización previa del representante legal de la entidad descentralizada (art. $4 .^{\circ}$ ).

g) Exigencia de constitución de garantías a cargo del contratista (art. $5^{\circ}$ ).

h) Obligación de contar con un interventor (art. 6. ${ }^{\circ}$ ).

i) Expedición de certificado de disponibilidad presupuestal previo a la celebración del contrato y de registro presupuestal (art. 7. ${ }^{\circ}$ y 14 ).

j) Inexistencia de relación laboral entre las personas vinculadas por el contratista y la entidad estatal (art. $8 .^{\circ}$ ). 9..$^{\circ}$.

k) Cumplimiento del régimen de inhabilidades e incompatibilidades (art.

1) Destinación exclusiva de los recursos recibidos por la entidad sin ánimo de lucro a la ejecución del objeto convenido (art. 11).

m) Constitución de la entidad sin ánimo de lucro con mínimo seis meses de antelación a la celebración del contrato y mantenimiento de vigencia de la personería jurídica por el término del contrato y un año más (arts. 12 y 13).

n) Procedencia de la terminación unilateral del convenio por parte de la entidad estatal (art. 15).

o) Requisitos especiales para los convenios de esta naturaleza celebrados en el sector de la salud (arts. 17 a 23).

A continuación se hace un análisis de las características de los convenios de interés público, a partir de la regulación introducida en el Decreto 092 de 2017 y de algunos desarrollos jurisprudenciales y doctrinarios sobre la materia.

\subsection{Características del convenio de interés público en la reglamentación contenida en el Decreto 092 de 2017}

\subsubsection{La regulación de estos convenios es una potestad del Gobierno Nacional, pero que no es exclusiva}

Del contenido del segundo inciso del artículo 355 de la Constitución se deduce que la competencia para reglamentar los convenios a los que se refiere dicho enunciado normativo es del Gobierno Nacional, pues establece en su 
frase final que "[e]l Gobierno Nacional reglamentará la materia". Tal ha sido la interpretación que a dicha disposición le ha dado la Corte Constitucional, como se infiere de la sentencia C-337 de $1993^{[38]}$. Sin embargo, en criterio del máximo tribunal de constitucionalidad, dicha competencia otorgada al Gobierno Nacional no impide un desarrollo por parte del Congreso de la República sobre esta materia, respetando el marco de la competencia atribuida por la Constitución, tal como lo expresó en la sentencia C-1250 de $2001^{[39]}$. Bajo este punto de vista, se puede entender por qué en la actualidad hay una regulación dual de la figura del convenio de interés público y del convenio de asociación, ambos fundados en el artículo 355 de la Constitución: una en el Decreto 092 de 2017 y otra en el artículo 96 de la Ley 489 de 1998, así como también en algunos artículos de dicho decreto ${ }^{40}$.

La cuestión de importancia que emerge de lo dicho tiene que ver con la pregunta referente a cuál debe prevalecer en caso de contradicción entre la regulación efectuada por el Gobierno Nacional, en aplicación del mandato contenido en el artículo 355 de la Constitución, y la del legislador, en virtud de la cláusula de libre configuración normativa que le confiere la carta superior. Al respecto, se considera que la solución más apropiada consiste en reconocer que, a pesar de tratarse de normas con igual jerarquía al desarrollar directamente la Constitución ${ }^{41}$, como el constituyente en este caso otorgó al Gobierno Nacional una competencia especial en materia reglamentaria para ser desarrollada a través de un reglamento autónomo constitucional ${ }^{42}$, la regulación de los convenios previstos en el segundo

38 Corte Constitucional, Sala Plena. Sentencia C-337 de 1993. M.P.: Vladimiro Naranjo Mesa.

39 Corte Constitucional, Sala Plena. Sentencia C-1250 de 2001. M.P.: Manuel José Cepeda Espinosa.

40 A pesar de ello, pudiera sostenerse que existen buenos argumentos para sustentar que la regulación que hizo el legislador de la figura de los convenios de asociación en el artículo 96 de la Ley 489 de 1998 constituye una vulneración de la competencia exclusiva y excluyente que el constituyente le otorgó al Gobierno Nacional sobre dicho tópico. Sin embargo, la Corte Constitucional, al analizar la exequibilidad de dicha norma, no hizo mención a dicho cargo y con otra motivación la declaró constitucional, por lo que sobre el particular pudiera afirmarse la existencia de cosa juzgada relativa frente a la decisión adoptada por el alto tribunal. Al respecto véase Corte Constitucional, Sala Plena. Sentencia C-671 de 1999. M.P.: Alfredo Beltrán Sierra.

41 Consejo de Estado, Sala de lo Contencioso Administrativo, Sección Tercera. Sentencia de 14 de agosto de 2008. C.P.: Mauricio Fajardo Gómez. Rad. 11001032600019990001201(16230); Consejo de Estado, Sala de lo Contencioso Administrativo, Sección Tercera. Auto del 5 de julio de 2017. C.P.: Jaime Orlando Santofimio Gamboa. Actor: Julián Andrés Cotes Buitrago y otros. Demandado: Departamento Nacional de Planeación. Rad. 111001-03-26-000-2017-00083-00 (59493).

42 Ha existido una álgida discusión en torno a la naturaleza jurídica del decreto expedido con fundamento en el artículo 355 superior. Si bien la Corte Constitucional ha utilizado el término "decreto autónomo constitucional" para referirse a este, dicha denominación no ha estado ausente de críticas por sus implicaciones jurídicas. Al respecto véase Corte Constitucional, Sala Plena. Sentencia C-1250 de 2001. M.P.: Manuel José Cepeda Espinosa, y salvamentos de voto 
inciso del artículo 355 debe prevalecer sobre la que lleve a cabo el legislador, en virtud del criterio de especialidad ${ }^{43}$.

\subsubsection{El objeto del convenio de interés público es restringido}

Es característica esencial de los convenios a los que se refiere el inciso segundo del artículo 355 de la Constitución que su objeto esté determinado por la realización de programas y actividades de interés público acordes con el Plan Nacional y los planes seccionales de desarrollo ${ }^{44}$. En similar sentido, la Corte Constitucional ha indicado que el objeto de estos convenios es el "desarrollo de actividades esencialmente benéficas, no como instrumento económico, sino con un propósito meramente asistencial y altruista, en el que a diferencia del pasado, no se privilegia la arbitrariedad y unilateralidad del gasto público, sino que se exige un grado aceptable de reciprocidad por parte del beneficiario de la ayuda" 45 .

Un programa o actividad es de interés público cuando persigue este propósito y no la satisfacción de un interés privado o egoísta ${ }^{46}$. Sin embargo, puede decirse que la satisfacción -por lo menos mediata- del interés público debe ser la finalidad de toda actuación estatal, y con mayor razón de la administrativa; es decir que no se trata de un asunto exclusivo de los convenios a los que se refiere el artículo 355 de la Constitución, sino de toda actuación contractual del Estado. Por lo tanto, ¿qué es, en realidad, lo que distingue el objeto de los convenios a los que se viene haciendo referencia y el del resto de contratos estatales, si en ambas categorías debe procurarse la garantía del interés público?

Si bien todo contrato celebrado por una entidad pública debe enmarcarse en la búsqueda de la satisfacción del bien común, los convenios que permite suscribir el segundo inciso del artículo 355 de la Constitución deben tener

a Corte Constitucional, Sala Plena. Sentencia C-1290 de 2001. M.P.: Álvaro Tafur Galvis. Para el Consejo de Estado, véase supra, nota 41. En la doctrina también hay posiciones encontradas entre quienes sostienen que este es un típico decreto constitucional autónomo, como RodRíGUEZ,

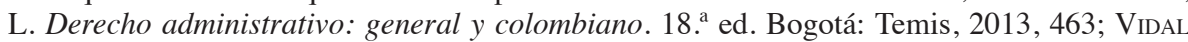
Perdomo, J. Derecho administrativo. 14. a ed. Bogotá: Legis, 2016, 35, y Chávez Marín. Los convenios de la Administración, cit., 377; y quienes lo niegan, como Quinche RAMírez, M. F. y URREgo Ortiz, F. Los decretos presidenciales en el sistema normativo. Bogotá: Doctrina y Ley, 2011, 255.

43 El criterio hermenéutico de lex specialis derogat generalis está consagrado en el sistema jurídico colombiano en el artículo 5. de la Ley 57 de 1887.

44 Corte Constitucional, Sala Plena. Sentencia C-324 de 2009. M.P.: Juan Carlos Henao Pérez. Así mismo, véase Rodríguez TAMAYo. Contratación pública con entidades sin ánimo de lucro, cit., 50-51.

45 Corte Constitucional, Sala Plena. Sentencia C-324 de 2009. M.P.: Juan Carlos Henao Pérez. En igual sentido, véase Corte Constitucional, Sala Plena. Sentencia C-027 de 2016.

46 Escola, H. J. El interés público como fundamento del derecho administrativo. Buenos Aires: Depalma, 1989, 249-250. 
por objeto la ejecución de programas o actividades de interés general, para los cuales la Administración Pública no adquiere la obligación de realizar un pago a favor del contratista, como contraprestación económica por su labor, en la medida en que este actúa como un sujeto que coopera para la finalidad conjunta querida por las partes. En esto se distinguen dichos convenios de otros contratos estatales, como, por ejemplo -citando, a propósito, solo dos ejemplos-, del contrato de obra pública, en el que la entidad le paga al contratista una suma de dinero por la actividad de construcción de un inmueble, o del contrato de suministro, en el que igualmente la Administración reconoce al contratista una contraprestación económica por los bienes o servicios entregados o cumplidos periódicamente. En este mismo sentido se pronuncia la Guía expedida por Colombia Compra Eficiente al señalar sobre el particular que "[1]a contratación autorizada por el artículo 355 de la Constitución Política no está encaminada a la adquisición de bienes y servicios y la ejecución de obras y en consecuencia no puede ser utilizada con ese propósito" ${ }^{47}$.

De igual manera, el segundo inciso del artículo 355 de la Constitución establece, como requisito para la celebración de los convenios a los que esta norma se refiere, que los programas o actividades de interés público sean acordes con el Plan Nacional y los planes seccionales de desarrollo. Por lo tanto, esta disposición se debe interpretar en armonía con los artículos 339 a 344 de la Constitución, que consagran la regulación de los planes de desarrollo ${ }^{48}$. Ahora bien, es importante anotar que el literal a) del artículo 2. ${ }^{\circ}$ del Decreto 092 de 2017 exige que, además de lo dicho anteriormente, el objeto de los contratos derivados del segundo inciso del artículo 355 superior

... corresponda directamente a programas y actividades de interés público previstos en el Plan Nacional o seccional de Desarrollo, de acuerdo con el nivel de la Entidad Estatal, con los cuales esta busque exclusivamente promover los derechos de personas en situación de debilidad manifiesta o indefensión, los derechos de las minorías, el derecho a la educación, el derecho a la paz, las manifestaciones artísticas, culturales, deportivas y de promoción de la diversidad étnica colombiana ${ }^{49}$.

Dicha previsión desborda la potestad reglamentaria del Gobierno Nacional concedida por el artículo 355 de la Constitución y, en tal medida, puede

47 Colombia Compra Eficiente. Guía, cit., 8.

48 Para un análisis de la regulación del Plan Nacional de Desarrollo y los planes seccionales de desarrollo en Colombia, véase Restrepo Salazar, J. C. Hacienda Pública. 9. a ed. Bogotá: Universidad Externado de Colombia, 2012, 449-466.

49 Según Colombia Compra Eficiente, “[e]stos aspectos coinciden con los sectores más desprotegidos". Colombia Compra Eficiente. Guía, cit., 8. 
considerarse viciada de nulidad, pues el segundo inciso de esta norma no calificó los programas o actividades que pueden ejecutar las entidades estatales mediante la celebración de tales convenios; es decir, no estableció un listado taxativo de labores o finalidades específicas vinculadas al objeto de dichos acuerdos, sino que únicamente exigió que se tratara de actividades de interés público acorde con los planes nacional y seccionales de desarrollo. Por lo tanto, establecer por vía reglamentaria que dichos convenios deben buscar "exclusivamente promover los derechos de personas en situación de debilidad manifiesta o indefensión, los derechos de las minorías, el derecho a la educación, el derecho a la paz, las manifestaciones artísticas, culturales, deportivas y de promoción de la diversidad étnica colombiana" es modificar el texto del segundo inciso del artículo 355 de la Constitución y no desarrollar una reglamentación del mismo ${ }^{50}$.

A pesar de ello, sobre la base de la presunción de legalidad y con pretensiones meramente ilustrativas, puede señalarse que el objeto de los convenios de interés público debe estar delimitado por los conceptos y nociones que se han venido desarrollando en la jurisprudencia constitucional y administrativa y que se exponen en la tabla 1. Para ello debe, además, es preciso en cuenta la inexistencia de definiciones legales al respecto y el carácter restrictivo y taxativo de dicha modalidad contractual.

50 Como lo ha expresado la doctrina, la potestad reglamentaria no puede ejercerse contrariando el contenido de la disposición superior reglamentada, es decir, menoscabando el principio de jerarquía normativa, pues este es uno de sus límites materiales. PARADA, R. Concepto y fuentes del derecho administrativo. Madrid: Marcial Pons, 2008, 59. De este principio se deriva que el reglamento puede desarrollar, o sea, definir las condiciones de aplicación de la disposición objeto de reglamentación, pero no puede restringir hasta ese punto su alcance cuando el creador del enunciado superior no lo limitó. Si el segundo inciso del artículo 355 de la Constitución establece que los convenios previstos en dicho texto normativo deben celebrarse para "impulsar programas y actividades de interés público", por más de que el mismo inciso señale que "[e]l Gobierno Nacional reglamentará la materia", es inadmisible la interpretación que considera que, por tanto, el Gobierno puede precisar en el reglamento el concepto jurídico indeterminado de "interés público", para reducirlo solo a pocas materias -que es lo que hace el artículo 2..$^{\circ}$ del Decreto 092 de 2017-, pues desconoce que si el constituyente no distinguió, no le es dable a quien reglamenta la Constitución hacerlo, menoscabando así el principio de jerarquía normativa, reflejado en este caso en el postulado de supremacía constitucional (arts. $4 .^{\circ}$ y 241 C.P.). Sobre los límites de la potestad reglamentaria véase también Consejo de Estado, Sala de lo Contencioso Administrativo, Sección Segunda, Subsección A. Sentencia del 6 de julio de 2017. C.P.: William Hernández Gómez. Actor: Fernando Quiroga Botero. Demandado: Nación. Rad. 11001-03-24-000-200800390-00(0585-09). 
TABLA 1. POBLACIÓN-OBJETO DE LOS CONVENIOS DE INTERÉS PÚBLICO

\begin{tabular}{|c|c|c|}
\hline $\begin{array}{l}\text { PoblaCIÓN-OBJETO DEL } \\
\text { CONVENIO DE INTERÉS PÚBLICO }\end{array}$ & \multicolumn{2}{|c|}{ EJEMPLOS A LA LUZ DE LA JURISPRUDENCIA CONSTITUCIONAL } \\
\hline $\begin{array}{l}\text { Personas en situación de } \\
\text { debilidad manifiesta }\end{array}$ & \multicolumn{2}{|c|}{$\begin{array}{l}\text { - Población en situación de desplazamiento } \\
\text { - Población carcelaria } \\
\text { - Personas de la tercera edad } \\
\text { - Enfermos catastróficos } \\
\text { - Niñas, niños y adolescentes } \\
\text { - Discapacitados físicos o psíquicos } \\
\text { - Víctimas del conflicto } \\
\text { - Eefensores de derechos humanos } \\
\text { - Entre otros }\end{array}$} \\
\hline $\begin{array}{l}\text { Personas en situación de } \\
\text { indefensión }\end{array}$ & \multicolumn{2}{|c|}{$\begin{array}{l}\text { La indefensión se ha definido como "una circunstancia empírica, no } \\
\text { normativa, que coloca a la persona en la imposibilidad real de ejercer } \\
\text { sus derechos fundamentales por motivos ajenos a su voluntad. Pese a } \\
\text { que, in abstracto, el ordenamiento jurídico dispone de medios de defensa } \\
\text { judicial para la protección de los derechos e intereses, en la práctica, } \\
\text { diversos factores de hecho, entre ellos la inacción de las autoridades } \\
\text { públicas, pueden dar lugar a la desprotección y consecuente indefensión } \\
\text { de una persona frente al poder o a la supremacía de otro particular" } \\
\text { (sentencia T- } 210 \text { de 1994). }\end{array}$} \\
\hline Minorías & \multicolumn{2}{|c|}{$\begin{array}{l}\text { - Étnicas: indígenas, afrocolombianos, raizales, rom. } \\
\text { - Políticas: parlamentarias, en oposición. } \\
\text { - "Discretas u ocultas": discapacidad en habla, oído o visión. } \\
\text { - Sexuales. }\end{array}$} \\
\hline Derecho a la educación & $\begin{array}{l}\text { Dimensiones: } \\
\text { - Preescolar } \\
\text { - Básica } \\
\text { - Primaria } \\
\text { - Secundaria } \\
\text { - Superior } \\
\text { - Etnoeducación } \\
\text { - Especial (deficiencia y } \\
\text { - capacidades extraordinarias) } \\
\text { - Sexual }\end{array}$ & $\begin{array}{l}\text { Factores: } \\
\text { - Acceso } \\
\text { - Permanencia } \\
\text { - Calidad } \\
\text { - Disponibilidad }\end{array}$ \\
\hline Derecho a la paz & \multicolumn{2}{|c|}{$\begin{array}{l}\text { Cumplimiento de los puntos del Acuerdo Final de Paz: } \\
\text { - Hacia un Nuevo Campo Colombiano: Reforma Rural Integral. } \\
\text { - Participación política: Apertura Democrática para Construir la Paz. } \\
\text { - Fin del conflicto: Acuerdo sobre el Cese al Fuego y de Hostilidades } \\
\text { Bilateral y Definitivo y Dejación de Armas. } \\
\text { - Solución al problema de las drogas Ilícitas. } \\
\text { - Acuerdo sobre las víctimas del conflicto: Sistema Integral de Verdad, } \\
\text { Justicia, Reparación y No Repetición. } \\
\text { - Implementación, verificación y refrendación. }\end{array}$} \\
\hline $\begin{array}{l}\text { Manifestaciones artísticas, } \\
\text { deportivas y culturales }\end{array}$ & \multicolumn{2}{|c|}{$\begin{array}{l}\text { - Arte: se ha definido como "cualquier actividad o producto reali- } \\
\text { zado por el ser humano con una finalidad estética o comunicativa, } \\
\text { a través del cual se expresan ideas, emociones o, en general, una } \\
\text { visión del mundo, mediante diversos recursos, como los plásticos, } \\
\text { lingüísticos, sonoros, o mixtos" (Consejo de Estado, Sala de lo } \\
\text { Contencioso Administrativo, Sección Tercera. Sentencia del } 2 \text { de } \\
\text { diciembre de 2013, exp. 41719). } \\
\text { - Deporte: se ha definido como el desarrollo de toda actividad física, } \\
\text { pudiendo comprender las dimensiones de "una forma de realización } \\
\text { personal, un espectáculo, una actividad laboral y una empresa" } \\
\text { (sentencia T-212 de 2016). }\end{array}$} \\
\hline
\end{tabular}




\begin{tabular}{|c|c|}
\hline $\begin{array}{l}\text { POBLACIÓN-OBJETO DEL } \\
\text { CONVENIO DE INTERÉS PÚBLICO }\end{array}$ & EJEMPLOS A LA LUZ DE LA JURISPRUDENCIA CONSTITUCIONAL \\
\hline & $\begin{array}{l}\text { - Cultura: se ha definido como "el conjunto de rasgos distintivos } \\
\text { espirituales y materiales, intelectuales y afectivos, que identifican a } \\
\text { una sociedad o a un grupo social y que abarca, además de las artes y } \\
\text { letras, los modos de vida, las maneras de vivir juntos, los sistemas de } \\
\text { valores, las tradiciones y las creencias" (sentencia C-111 de 2017). }\end{array}$ \\
\hline $\begin{array}{l}\text { Promoción de la diversidad } \\
\text { étnica }\end{array}$ & $\begin{array}{l}\text { Debe recaer en las siguientes poblaciones: } \\
\text { - Indígenas } \\
\text { - Afrocolombianos } \\
\text { - Raizales } \\
\text { - Rom }\end{array}$ \\
\hline
\end{tabular}

Fuente: elaboración propia.

\subsubsection{El convenio no puede comportar una relación conmutativa}

Otro rasgo que caracteriza a estos convenios, según el literal b del artículo $2 .^{\circ}$ del Decreto 092 de 2017, es que no pueden aparejar "una relación conmutativa en la cual haya una contraprestación directa a favor de la Entidad Estatal, ni instrucciones precisas dadas por esta al contratista para cumplir con el objeto del contrato" ${ }^{1}$. Para comprender el alcance de este requisito se debe hacer referencia al artículo 1498 del Código Civil, que contiene la distinción entre los contratos conmutativos y aleatorios, señalando que "[e]l contrato oneroso es conmutativo, cuando cada una de las partes se obliga a dar o hacer una cosa que se mira como equivalente a lo que la otra parte debe dar o hacer a su vez; y si el equivalente consiste en una contingencia incierta de ganancia o pérdida, se llama aleatorio" 52 .

De este modo, cuando el citado literal b del artículo $2 .{ }^{\circ}$ prohíbe que se cree una relación conmutativa en el contrato que se celebre al amparo del segundo inciso del artículo 355 de la Constitución, proscribe que dicho convenio sea oneroso o produzca obligaciones que se miren como equivalentes, tal como sucede cuando surge la obligación de pago como respuesta a la obligación de ejecución de una obra, prestación de un servicio o suministro de un bien, que a su vez son correlativas a la obligación de pago $^{53}$. En tales casos la causa de la obligación de una de las partes está constituida por la obligación de la otra parte.

51 Como lo indica Rodríguez Tamayo, el convenio de interés público no puede generar un beneficio directo para la entidad estatal, ni prestaciones equivalentes. Véase RodríGuez TAMAYO. Contratación pública con entidades sin ánimo de lucro, cit., 52-54. En similar sentido, CHÁvez MARín. Los convenios de la Administración, cit., 77 y 386.

52 Sin embargo, un sector de la doctrina ha puesto de presente la inexactitud de esta clasificación. Véase Ospina Fernández, G. y Ospina Acosta, E. Teoría general del contrato y del negocio jurídico. 7. . ed. Bogotá: Temis, 2005, 63.

53 Como lo indicó la Agencia de Contratación Pública Colombia Compra Eficiente: "El contrato de colaboración suscrito en desarrollo del artículo 355 de la Constitución Política y el Decreto 092 de 2017 no es conmutativo y por tanto la Entidad Estatal contratante no instruye a la entidad privada sin ánimo de lucro para desarrollar los programas o actividades previstas, 
En consecuencia, la relación propia de los convenios de interés público es el nexo obligacional que se constituye entre las partes -entidad estatal y persona sin ánimo de lucro- para la realización de una actividad o programa de interés público acorde con los planes nacional o seccionales de desarrollo, en virtud del cual cada una se compromete a aportar recursos y labores tendientes al logro de la finalidad que, en forma mancomunada, se busca alcanzar. Pero ninguna de las partes adquiere la obligación de pagarle a la otra por la ejecución de sus funciones.

Ahora bien, la prohibición de dar "instrucciones precisas" al contratista, por parte de la entidad estatal, es problemática, porque podría interpretarse como una permisión para que esta se desentienda de la ejecución del convenio. Sin embargo, no es esta la interpretación válida, pues, al resultar aplicable el artículo 83 de la Ley 1474 de 2011 -en virtud de la remisión que efectúa el artículo 8. ${ }^{\circ}$ del Decreto 092 de 2017-, el supervisor o interventor, según sea el caso, deberá realizar el seguimiento técnico, administrativo, financiero y jurídico correspondiente. Además, como lo indicó la Agencia de Contratación Pública Colombia Compra Eficiente, las reglas generales que la entidad estatal debe impartir no se incluyen dentro del concepto de instrucciones precisas ${ }^{54}$.

\subsubsection{Las entidades privadas con las que se pretenda celebrar el convenio deben ser sin ánimo de lucro y de reconocida idoneidad, para lo cual se deben observar los procedimientos y demás requisitos previstos en el Decreto 092 de 2017}

Como de manera clara lo expresa el texto constitucional al que se ha hecho alusión, los convenios celebrados por las entidades estatales para impulsar programas o actividades de interés público acordes con los planes nacional y seccionales de desarrollo únicamente pueden suscribirse con entidades privadas sin ánimo de lucro y de reconocida idoneidad ${ }^{55}$. Por otra parte, el

sino que se asocian para desarrollar un programa o actividad del plan de desarrollo en beneficio de la población en general". Colombia Compra Eficiente. Circular Externa Única, cit., 64.

54 Colombia Compra Eficiente, Guía, cit., p. 9. En similar sentido, Rodríguez Tamayo plantea que la prohibición de emitir instrucciones precisas al contratista se justifica por la idoneidad que motivó la escogencia de la ESAL, pero que esto no se opone a que la entidad estatal exija en la fase de planeación unas condiciones mínimas que orienten la ejecución del contrato, ni a que supervise (vigile) el cumplimiento de las obligaciones del contratista. Véase RodRíGuEZ TAMaYo. Contratación pública con entidades sin ánimo de lucro, cit., 55-56.

55 Corte Constitucional, Sala Plena. Sentencia C-543 de 2001. M.P.: Álvaro Tafur Galvis. Según Chávez Marín, las personas jurídicas sin ánimo de lucro son aquellas "que trabajan por el beneficio o utilidad común y que como su nombre lo indica con una expresión negativa, no buscan satisfacer intereses lucrativos en su favor o en favor de quienes las integran y, por ende, no implican el reparto de utilidades entre sus miembros con ocasión de su liquidación o en los períodos contables, sino que sus utilidades deben revertir o acrecer al objeto social respectivo", como las fundaciones, las corporaciones y las organizaciones de economía solidaria. Véase Chávez Marín. Los convenios de la Administración, cit., 380-383. 
artículo 3. ${ }^{\circ}$ del Decreto 092 de 2017 establece la exigencia de la reconocida idoneidad $^{56}$ de las personas sin ánimo de lucro. Sobre los elementos que es preciso valorar con el fin de sostener la idoneidad y el reconocimiento de una entidad privada sin ánimo de lucro, la Guía expedida por Colombia Compra Eficiente para la materia propone, de manera meramente ilustrativa, los criterios que se sintetizan en la tabla 2 .

TABLA 2. CRITERIOS DE IDONEIDAD Y RECONOCIMIENTO EPSAL

\begin{tabular}{|c|c|}
\hline Criterios & $\begin{array}{l}\text { POSIBLES INDICADORES DEL CUMPLIMIENTO } \\
\text { DE LOS CRITERIOS }\end{array}$ \\
\hline $\begin{array}{l}\text { Correspondencia del objeto de } \\
\text { la entidad privada sin ánimo de } \\
\text { lucro y el programa o actividad } \\
\text { previsto }\end{array}$ & $\begin{array}{l}\text { Coincidencia de los documentos constitutivos de la organización y } \\
\text { la línea, proyecto o actividad del plan de desarrollo correspondiente. }\end{array}$ \\
\hline $\begin{array}{l}\text { Capacidad del personal de la } \\
\text { entidad privada sin ánimo de } \\
\text { lucro }\end{array}$ & $\begin{array}{l}\text { Evidenciar el equipo misional, técnico y administrativo del que } \\
\text { dispone la organización para desarrollar el objeto del convenio. }\end{array}$ \\
\hline Experiencia & $\begin{array}{l}\text { - Esta debe estar asociada al desarrollo exitoso de programas simi- } \\
\text { lares o afines tanto con otras entidades privadas como públicas. } \\
\text { - En tanto estas no deberán estar inscritas en el RuP, dichas certi- } \\
\text { ficaciones serán a través de documentos privados que deberán } \\
\text { evaluarse por la entidad pública contratante. } \\
\text { - La experiencia puede ser aportada por los fundadores de la } \\
\text { organización. }\end{array}$ \\
\hline Estructura organizacional & $\begin{array}{l}\text { - Existencia de un gobierno corporativo. } \\
\text { - Estados financieros. } \\
\text { - Política documentada de conflicto de intereses. } \\
\text { - Política de manejo de riesgos operativos y archivos de do- } \\
\text { cumentos. } \\
\text { - Política documentada de compensación de administradores y } \\
\text { miembros de junta. }\end{array}$ \\
\hline $\begin{array}{l}\text { Indicadores de la eficiencia de la } \\
\text { organización }\end{array}$ & $\begin{array}{l}\text { - Calificación de régimen tributario especial al que se refiere el } \\
\text { artículo 356-2 del Estatuto Tributario. } \\
\text { - Indicador de la eficiencia en la administración del gasto en } \\
\text { funcionamiento. } \\
\text { - Indicador de la eficacia del esfuerzo de la entidad sin ánimo de } \\
\text { lucro para procurar contribuciones del sector privado. }\end{array}$ \\
\hline Reputación & $\begin{array}{l}\text { - Antecedentes fiscales, disciplinarios y penales de los adminis- } \\
\text { tradores de la organización. } \\
\text { - Identificar la relación de personas políticamente expuesta con } \\
\text { la organización. } \\
\text { - Encuestas o sondeos sobre la reputación de la organización. } \\
\text { - Evaluación del cumplimiento previo en proyectos por parte } \\
\text { de la organización. }\end{array}$ \\
\hline
\end{tabular}

Fuente: elaboración propia, con base en la Guía de Colombia Compra Eficiente.

56 La reconocida idoneidad debe estar basada en la experiencia de la ESAL en la ejecución de actividades de interés público, con entidades estatales o particulares. En tal sentido, véase Rodríguez Tamayo. Contratación pública con entidades sin ánimo de lucro, cit., 30-34. 
Asimismo, en la nueva reglamentación, el Gobierno Nacional ha supeditado la celebración de estos contratos con las entidades sin ánimo de lucro a:

Que no exista oferta en el mercado de los bienes, obras y servicios requeridos para la estrategia y política del plan de desarrollo objeto de la contratación, distinta de la oferta que hacen las entidades privadas sin ánimo de lucro; o que, si existe, la contratación con entidades privadas sin ánimo de lucro represente la optimización de los recursos públicos en términos de eficiencia, eficacia, economía y manejo del Riesgo. En los demás eventos, la Entidad Estatal deberá aplicar la Ley 80 de 1993, sus modificaciones y reglamentos.

Además, a partir de la vigencia del Decreto 092 de 2017, la contratación de la entidad privada sin ánimo de lucro y de reconocida idoneidad debe estar precedida de un proceso de selección plural o competitivo, cuando exista más de una entidad de estas características. Esto es lo que establece el artículo 4..$^{\circ}$ del mencionado decreto. En este sentido, si las actividades o programas de interés público requeridos para cumplir con los planes nacional o seccionales de desarrollo se ofrecen en el mercado, en principio, se deben realizar los procesos de selección aplicables, de acuerdo con el EGCAP, así existan entidades privadas sin ánimo de lucro que también los ofrezcan, salvo que la contratación con estas entidades se justifique por razones de optimización de recursos públicos. Sobre cuándo se puede afirmar que existe optimización de recursos, la Guía de Colombia Compra Eficiente en la materia propone tres situaciones fácticas que servirían para justificar dicha situación ${ }^{57}$. En primer lugar, cuando sea difícil pactar de manera precisa y determinable los resultados del contrato; en segundo lugar, cuando los usuarios y la entidad estatal contratante tengan dificultad para determinar la prestación del servicio; y tercero, cuando el proveedor privado cuente con incentivos para reducir costos en detrimento de los ciudadanos destinatarios del bien o servicio. Frente a estos tres supuestos, valga destacar que no deben interpretarse como taxativos, y que en la fase de planeación se podrán identificar estas u otras situaciones que permitan afirmar un mayor valor por los recursos invertidos para el logro de los objetivos de los respectivos planes de desarrollo. En cualquier caso, ello no debe confundirse con obtener el precio más bajo posible, consistiendo más bien en tener en consideración los otros principios orientadores, como la eficiencia, la eficacia y el manejo de riesgos derivados de la gestión contractual.

Por otra parte, en el evento en que aparezca justificada la realización del convenio con la entidad privada sin ánimo de lucro de reconocida idoneidad, este podrá celebrarse de manera directa, siempre y cuando no existan otras entidades de las mismas características que ofrezcan los bienes, obras 
o servicios requeridos. En caso de que haya pluralidad de entidades de esta naturaleza, se debe llevar a cabo un proceso competitivo, que garantice la libre concurrencia y la selección objetiva de la oferta ${ }^{58}$. Sin embargo, dicho proceso competitivo no resultará obligatorio cuando el objeto del proceso "corresponde a actividades artísticas, culturales, deportivas y de promoción de la diversidad étnica colombiana, que solo pueden desarrollar determinadas personas naturales o jurídicas", a la luz del inciso final del artículo 4 . $^{\circ}$ del decreto en mención. El Decreto 092 de 2017 también contempla otra exigencia para la celebración de estos convenios con entidades privadas sin ánimo de lucro y de reconocida idoneidad, como la obligación que estas tienen de registrarse en el Sistema Electrónico de Contratación Pública (SECOP), si aspiran a contratar bajo esta modalidad, ya que dicha herramienta electrónica operará como "el medio para acreditar los indicadores de idoneidad, experiencia, eficiencia, economía y de manejo del riesgo definidos por las Entidades Estatales" (art. 9. 'ibíd.). Sin embargo, al tenor del artículo 10. ${ }^{\circ}$ del mencionado reglamento, "[1]as Entidades Estatales no requerirán la inscripción de las entidades privadas sin ánimo de lucro en el RUP para la contratación a la que hace referencia el presente decreto".

Por último, sobre el origen nacional de las entidades privadas sin ánimo de lucro, si bien el Decreto 092 de 2017 guarda silencio al respecto, compartimos la interpretación que del mismo hace la Guía de Colombia Compra Eficiente ${ }^{59}$ al señalar que nada obsta para que dicha entidad sea de carácter extranjero. De esta interpretación valga únicamente advertir que en caso de que esta pueda caracterizarse como un organismo de cooperación, asistencia o ayuda internacional, la regulación aplicable será la dispuesta por el artículo 20 de la Ley 1150 de 2007, atendiendo al criterio hermenéutico de especialidad.

\subsubsection{Su celebración requiere de autorización previa,} por parte del representante legal de la entidad estatal

Los incisos tercero y cuarto del artículo 2. ${ }^{\circ}$ del Decreto 092 de 2017 también exigen que las entidades estatales que aspiren a celebrar los convenios para impulsar los programas y actividades a que se refiere el artículo 355 de la Constitución cuenten con "previa autorización expresa de su representante legal para cada contrato en particular que la Entidad Estatal planee suscribir bajo esta modalidad", facultad de autorización que, al tenor de la norma, el

58 Según Colombia Compra Eficiente, "[e]l proceso competitivo se entiende como el proceso de selección en el que hay una libre concurrencia y pluralidad de interesados, correspondiendo esto con la regulación de licitación pública del artículo 860 del Código de Comercio y del artículo 30 de la Ley 80 de 1993”. Colombia Compra Eficiente. Circular Externa Única, cit., 68. En similar sentido, véase Rodríguez TAmaYo. Contratación pública con entidades sin ánimo de lucro, cit., 60.

59 Colombia Compra Eficiente. Guía, cit., 10. 
representante legal no podrá delegar. Además, dispone que dicha autorización deberá acreditarse en los documentos de proceso. Con ello se da continuidad y uniformidad al requisito de justificación previa de la causal de modalidad de selección a utilizarse que establece el parágrafo $1 .^{\circ}$ del artículo $2 .^{\circ}$ de la Ley 1150 de 2017 y que se ha interpretado como un "imperativo legal vigente" 60 , que desarrolla los principios de transparencia y publicidad que deben regir los procedimientos contractuales.

\subsubsection{A estos convenios les resultan aplicables tanto el régimen}

de prohibiciones, inhabilidades e incompatibilidades, como los principios de la contratación estatal

Tal como lo hace el artículo 13 de la Ley 1150 de 2007, respecto de la actividad contractual regulada por regímenes exceptuados del EGCAP, los artículos 6..$^{\circ}$ y $7 .^{\circ}$ del Decreto 092 de 2017 extienden el régimen de prohibiciones, inhabilidades e incompatibilidades, así como los principios de la contratación estatal, a la celebración de convenios para el impulso de programas o actividades de interés público. Si bien sobre las inhabilidades e incompatibilidades dispuestas en el EGCAP se había discutido inicialmente si estas eran aplicables a los convenios de asociación, en razón de la especificidad de su régimen contractual, ya el Consejo de Estado se había decantado por considerar:

... el hecho de que a cierta clase de contratos que celebre la Administración le sean aplicables normas de regímenes especiales, no quiere decir que la observancia de las causales de incompatibilidad e inhabilidad deba reducirse a lo allí consagrado y excluir la aplicación del régimen general.

Al contrario, una interpretación armónica y sistemática del ordenamiento obliga a tener en cuenta todas las normas encaminadas a que las actuaciones de los servidores públicos se desarrollen de manera transparente e imparcial, esto es, aquellas que tengan como propósito evitar que el interés personal de quien ejerce una función pública no entre en conflicto con las funciones que desempeña, así como con los deberes y obligaciones propias de su cargo ${ }^{61}$.

Sin embargo, para no dejar ninguna duda al respecto, el artículo $6 .^{\circ}$ del Decreto 092 de 2017 dispuso expresamente que "[1] as prohibiciones, inhabilidades e incompatibilidades establecidas en la Constitución y en las Leyes 80 de 1993,

60 Consejo de Estado, Sala de lo Contencioso Administrativo, Sección Tercera. Sentencia del 14 de mayo de 2014. C.P.: Mauricio Fajardo Gómez. Actor: Martín Bermúdez Muñoz. Demandado: Departamento Nacional de Planeación. Rad. 1100110326000201400035 00(50222).

61 Consejo de Estado, Sala de lo Contencioso Administrativo, Sección Tercera, Subsección B. Sentencia del 5 de diciembre de 2016. C.P.: Ramiro Pazos Guerrero. Exp. 41333. Rad. 05001233100020030366301. 
1150 de 2007 y 1474 de 2011, y en las normas que las modifiquen, aclaren, adicionen o sustituyan, o en cualquier otra norma especial, son aplicables a la contratación a la que hace referencia el presente decreto". Por su parte, el artículo $7 .^{\circ}$ del mismo cuerpo normativo torna exigibles los principios de la contratación estatal. Además, con mayor razón, los artículos 209 y 267 de la Constitución, que consagran los principios de la función administrativa y de la gestión fiscal, respectivamente, también resultan aplicables a esta actividad.

\subsubsection{Se rigen por las normas especiales del artículo 355}

de la Constitución, el Decreto 092 de 2017 y, subsidiariamente, por las normas del EGCAP

Uno de los principales cambios introducidos por el Decreto 092 de 2017 sobre la reglamentación de los convenios derivados del segundo inciso del artículo 355 de la Constitución Política fue establecer como régimen de base el previsto en el EGCAP, pues recuérdese que el Decreto 777 de 1992 disponía que las normas aplicables a tales convenios eran las del derecho privado, salvo en algunos supuestos en los que sí resultaba aplicable la Ley 80 de 1993, como sucedía con la inclusión y utilización de cláusulas excepcionales ${ }^{62}$. Por tal razón, en el referido pronunciamiento se planteó que la liquidación era un trámite que no resultaba obligatorio en los convenios regulados por el Decreto 777 de 1992, ya que esta era una exigencia contenida en el artículo 60 de la Ley 80 de 1993 para los contratos regidos por el EGCAP, y no para los sometidos a las normas civiles. Esta misma posición había sido sostenida recientemente por la Sala Penal de la Corte Suprema de Justicia ${ }^{63}$.

Sin embargo, como se expresó al comienzo, el Decreto 092 de 2017 introduce un cambio relevante en tal sentido, porque en su artículo $8 .^{\circ}$ dispone que "[1]a contratación a la que hace referencia el presente decreto está sujeta a las normas generales aplicables a la contratación pública excepto en lo reglamentado en el presente decreto" ${ }^{\circ 4}$. Ello significa que a partir del $1 .^{\circ}$

62 Consejo de Estado, Sala de lo Contencioso Administrativo, Sección Tercera, Subsección C. Sentencia del 3 de diciembre de 2014. C.P.: Olga Mélida Valle de De La Hoz. Actor: Asociación Promotora de Proyectos Servicios y Asesoría Culturales Proactiva y otros. Demandado: Bogotá - Distrito Capital - Secretaría Distrital de Integración Social. Rad. 25000-23-36-0002014-00199-01(51832).

63 Corte Suprema de Justicia, Sala Penal. Sentencia del 25 de enero de 2017. M.P.: Patricia Salazar Cuéllar. Proceso 48.250.

64 La remisión contenida en el artículo 8..$^{\circ}$ del Decreto 092 de 2017 se ha interpretado acertadamente como la aplicación vinculante de las normas previstas en las leyes 80 de 1993, 1150 de 2007 y 1474 de 2011, y en los decretos 19 de 2012 y 1082 de 2015, así como de las normas civiles y comerciales (al tenor de los artículos 13, 32 y 40 de la Ley 80), en todo aquello que no esté expresamente regulado en el Decreto 092 de 2017 y sea compatible con este. Lo anterior significa que instituciones como el deber de planeación de la contratación estatal (estudios previos), la solemnidad del contrato estatal (exigencia de que conste por escrito), el 
de junio de 2017, las normas del EGCAP, esto es, las de las leyes 80 de 1993 y 1150 de 2007 y, en lo correspondiente, las de la Ley 1474 de 2011, rigen para la celebración de los convenios celebrados en virtud del segundo inciso del artículo 355 superior, salvo en lo expresamente regulado en el Decreto 092 de 2017. Es decir que el derecho privado solo resultará aplicable por la remisión que realizan los artículos 13, 32 y 40 de la Ley 80 de 1993. En otras palabras, el orden de prelación normativo para la celebración de estos convenios será el siguiente: en primer lugar, se deberá aplicar el artículo 355 de la Constitución; en segundo lugar, el Decreto 092 de 2017; en tercer lugar -en lo no regulado en aquel- el EGCAP y, en cuarto lugar, el derecho privado, básicamente en lo que respecta al alcance de la autonomía de la voluntad. Lo anterior implica reconocer, por consiguiente, que en vigencia del Decreto 092 de 2017 la liquidación sí resultará obligatoria en los convenios de interés público, al igual que las demás disposiciones del EGCAP, que consagran requisitos o procedimientos, que no contradicen los contemplados en el referido decreto. En sentido contrario a esta interpretación, la Guía publicada por Colombia Compra Eficiente parece plantear la liquidación como una fase discrecional por las partes y condicionada a que ello sea necesario ${ }^{65}$.

\section{EL CONVENIO DE ASOCIACIÓN}

\subsection{Concepto y fundamento normativo}

A partir de lo señalado, los convenios de asociación son una modalidad de contrato estatal prevista en el artículo 96 de la Ley 489 de 1998. Tal y como se desprende de su contenido, dichos convenios deberán celebrarse de acuerdo con lo dispuesto por el artículo 355 constitucional, por lo que para su adecuada comprensión habrá de hacerse la debida integración normativa. En este sentido se ha pronunciado la Corte Constitucional, quien al declarar la exequibilidad del artículo 96 de la Ley 489 de 1998 advirtió que su contenido en ningún caso podría ser utilizado para contrariar los condicionamientos realizados en la mencionada norma constitucional ${ }^{66}$. Por lo tanto, conviene en este punto recordar los condicionamientos que en materia contractual hace

cumplimiento de los requisitos de ejecución, los deberes de dirección de la entidad estatal (incluyendo la posibilidad de imponer la multa y la cláusula penal pecuniaria), la supervisión y la interventoría, las garantías y la posibilidad de decretar el siniestro, entre otras, también aplican para los convenios celebrados al amparo del Decreto 092 de 2017. Para un completo análisis de estos temas véase Rodríguez TAMAYo. Contratación pública con entidades sin ánimo de lucro, cit., 11-150.

65 Colombia Compra Eficiente. Guía, cit., 21.

66 Corte Constitucional, Sala Plena. Sentencia C-671 de 1999. M.P.: Alfredo Beltrán Sierra. 
el artículo 355 de la Carta Política. Al respecto, tras prohibir las donaciones en favor de personas naturales o jurídicas de derecho privado por parte de cualquier rama del poder público por razones de mera liberalidad, el inciso segundo del artículo en mención plantea, al menos, tres condiciones para su celebración, a saber: 1. Que se realice con una entidad sin ánimo de lucro de reconocida idoneidad; 2. Que la finalidad del contrato sea el impulso de programas o actividades de interés público, y 3 . Que estos programas o actividades se encuentren acordes con el plan nacional y los planes territoriales de desarrollo.

A partir de lo expuesto, de la integración normativa de ambas disposiciones podría definirse el convenio de asociación como aquel acuerdo de voluntades celebrado por cualquier entidad pública con una entidad privada sin ánimo de lucro de reconocida idoneidad con el objeto de asociarse para el desarrollo de un conjunto de actividades o programas de interés público que guarden relación con los cometidos y funciones públicas que les asigna a aquellas la ley y que sean acordes con los planes de desarrollo correspondientes ${ }^{67}$. En la celebración de dichos convenios deberá darse aplicación estricta a los principios del artículo 209 superior; además, por expresa disposición legal, estos deben constar por escrito, estableciéndose con precisión su objeto, término, obligaciones de las partes, aportes y coordinación.

\subsection{Características del convenio de asociación previsto en el artículo 96 de la Ley 489 de 1998}

\subsubsection{El convenio de asociación puede celebrarse por cualquier entidad estatal}

El que la celebración de los convenios de asociación pueda realizarse por cualquier entidad estatal se deriva del tenor literal del artículo 96 de la Ley 489 de 1998 que dispone que corresponde a "las entidades estatales, cualquiera sea su naturaleza y orden administrativo". En este sentido, serán competentes para celebrar este tipo de convenios todas las entidades enlistadas en el artículo $2 .^{\circ}$ del EGCAP. En este punto, existe una importante diferencia con los convenios que se encontraban regidos por el Decreto 777 de 1992 y ahora por el Decreto 092 de 2017, ya que estos son competencia exclusiva de los gobiernos Nacional, departamental, distrital y municipal, es decir que no podrán ser celebrados por entidades estatales que no pertenezcan a la rama

67 Consejo de Estado, Sala de lo Contencioso Administrativo, Sección Tercera, Subsección C. Sentencia del 3 de diciembre de 2014. C.P.: Olga Mélida Valle de De la Hoz. Actor: Asociación Promotora de Proyectos Servicios y Asesoría Culturales Proactiva y otros. Demandado: Bogotá - Distrito Capital - Secretaría Distrital de Integración Social. Rad. 25000-23-36-0002014-00199-01(51832). 
ejecutiva -esto, según la interpretación de Colombia Compra Eficiente- ${ }^{68}$. En este sentido se había pronunciado la Sala de Consulta y Servicio Civil al señalar que "[1]os dos primeros incisos del artículo 96 de la ley 489 de 1998 regulan los 'Convenios de Asociación' que pueden suscribir las entidades estatales de todo orden, con personas jurídicas particulares de conformidad con lo dispuesto por el artículo 355 de la Constitución Política" ${ }^{69}$.

4.2.2. El contratista deberá ser igualmente una entidad particular sin ánimo de lucro y de reconocida idoneidad

En principio, el artículo 96 de la Ley 489 de 1998 señala que los sujetos con los que procede la contratación son "personas jurídicas particulares", de lo cual se desprende que excluye a las personas naturales y, además, a las personas jurídicas de naturaleza pública. Por otro lado, se advierte que dicha disposición legal no establece expresamente si las personas jurídicas privadas pueden o no tener ánimo de lucro, ni menciona los requisitos de reconocimiento e idoneidad. $\mathrm{Al}$ respecto, atendiendo al criterio de jerarquía normativa, por la remisión que el artículo legal hace al artículo 355 de la Constitución, se considera que la calidad del contratista en los convenios de asociación debe ser exclusivamente la de una persona jurídica privadas sin ánimo de lucro ${ }^{70}$. Dicha posición se refuerza por lo dispuesto en el artículo $5 .{ }^{\circ}$ del Decreto 092 de 2017, al regular exclusivamente los convenios de asociación como aquellos celebrados por entidades privadas sin ánimo de lucro ${ }^{71}$.

La misma suerte debe seguir el requisito de reconocida idoneidad, es decir que esta será una condición que deberá cumplir el contratista asociado. En cuanto a su significado, debe partirse de que este es un concepto que carece de definición legal para este tipo de contrato, ya que la prevista en el artículo 3. ${ }^{\circ}$ del Decreto 092 de 2017 solo es vinculante para los convenios definidos en el artículo $2 .^{\circ}$ del mismo. Sin embargo, de forma ilustrativa puede recurrirse a ella para afirmar que se refiere a que la entidad sin ánimo de lucro debe ser "adecuada y apropiada para desarrollar las actividades que son objeto del proceso de contratación y cuenta con experiencia en el objeto a contratar"72,

68 Colombia Compra Eficiente. Guía, cit., 7. Así también lo indicó esta agencia en la Circular Externa Única, cit., p. 64.

69 Consejo de Estado, Sala Consulta y Servicio Civil. Concepto 1957 del 3 de septiembre de 2009. C.P.: Enrique José Arboleda Perdomo.

70 En sentido contrario se pronuncia Dávila Vinueza al afirmar: "No podrán celebrarse con personas naturales, ya que la norma expresamente hace alusión a personas jurídicas; aunque no se hace distinción en su aplicación entre personas jurídicas sin ánimo de lucro (asociaciones, fundaciones o corporaciones), o con ánimo de lucro (sociedades civiles o comerciales de cualquier tipo". Dávila VInUEZA, L. G. Régimen jurídico de la contratación estatal. 3. a ed., Bogotá: Legis, 2016, 469.

71 Colombia Compra Eficiente. Guía, cit., 7.

72 Decreto 092 de 2017 del Departamento Nacional de Planeación, cit., art. 3.․ 
dejando a la entidad pública la libertad de determinar las condiciones que permitan llegar a dicha convicción en los estudios y documentos previos, y atendiendo a las particularidades de cada convenio.

A manera ilustrativa, algunos criterios que podrían utilizarse para acreditar el reconocimiento de la idoneidad son: (i) capacidad financiera, (ii) capacidad técnica y administrativa, (iii) tiempo de constitución, (iv) especialidad en la ejecución de actividades similares y (iv) experiencia específica. Debe advertirse en este punto que, al ser estos criterios susceptibles de cumplimiento particular e individualizado por cada entidad sin ánimo de lucro, deben gozar de suficiente justificación técnica y objetiva para que se adecuen al cumplimiento de los principios que inspiran la contratación estatal, en particular los descritos en el artículo 209 constitucional. Por último, debe señalarse que la entidad privada podrá ser igualmente extranjera, con la advertencia hecha previamente.

4.2.3. El objeto del convenio de asociación es el desarrollo de cometidos y/o funciones públicas propias de las entidades estatales

Sea lo primero reiterar que en virtud del condicionamiento que realiza el segundo inciso del artículo 96 de la Ley 489, al remitirse a lo dispuesto en el artículo 355 constitucional, dichos convenios de asociación no podrán en ningún caso utilizarse para el otorgamiento de auxilios o donaciones, atendiendo a la mera liberalidad de los poderes públicos, tal y como lo impone el inciso primero del artículo constitucional en mención ${ }^{73}$. De lo anterior se concluye que el interés perseguido con la contratación debe ser de carácter general o colectivo, materializado en los cometidos y funciones que le han sido asignados en el ordenamiento jurídico a la entidad estatal contratante. Así, en el caso de una entidad territorial se debe garantizar que los fines del convenio de asociación a celebrarse sean acordes con los fines y funciones asignados en la Constitución, leyes orgánicas y ordinarias correspondientes, al igual que en sus correspondientes planes de desarrollo. Además, si se trata de cualquier otra entidad estatal, deberá indagarse igualmente por su finalidad y competencia en las normas legales correspondientes, incluyendo sus actos de creación y los asimilables a los planes de desarrollo, para garantizar el cumplimiento de los mismos a través del convenio a celebrarse.

En cuanto a la diferencia entre los objetos de los convenios de interés público y los de asociación, y con el fin de garantizar la diferenciación hecha por el artículo 5..$^{\circ}$ del Decreto 092 de 2017, puede señalarse que mientras el primero busca el impulso de programas y actividades de interés público, que estén acordes con los planes de desarrollo y que les sean propios a las

73 Consejo de Estado, Sala de Consulta y Servicio Civil. Concepto 1710 del 23 de febrero de 2006. C.P.: Luis Fernando Álvarez Jaramillo. 
entidades sin ánimo de lucro, en los convenios de asociación dicho objeto es más amplio, al tener como único referente los cometidos y funciones que la ley le ha asignado a la entidad pública contratante. En este sentido, la restricción en el objeto de los convenios establecido en el literal a del artículo 2. ${ }^{\circ}$ del Decreto 092 de 2017 no les es aplicable a los convenios de asociación, en virtud de lo dispuesto en el inciso final del artículo $5 .^{\circ}$ del mencionado decreto.

\subsubsection{No puede haber remuneración sino aportes de los asociados}

Debido al objeto antes descrito, el convenio de asociación es una figura donde las partes asociadas suman voluntades y recursos para que sean utilizados en el desarrollo del acuerdo. En este sentido, repugna a este tipo de convenio la remuneración o utilidad, ya sea en forma de gastos de administración o de honorarios por parte del contratista-asociado a esta modalidad contractual, lo que implica que todos los aportes deberán ser destinados exclusivamente al desarrollo del objeto. De allí que el mismo tenor literal del artículo 96 de la Ley 489 de 1998 haga mención a "aportes" y "coordinación" como elementos indispensables para su configuración.

En este punto encontramos otra diferencia con los convenios de interés público, en tanto los de asociación requieren siempre de aportes o contrapartidas mutuas entre los asociados, mientras que los primeros podrán tener aportes únicamente por parte de la entidad estatal contratante ${ }^{74}$. La magnitud de dichos aportes para los convenios de asociación debe definirse, por regla general, por cada entidad estatal en sus correspondientes manuales de contratación. En este mismo sentido, en los convenios de asociación no se configuran, en rigor, pagos, sino desembolsos de los aportes, los cuales son inherentes a la modalidad de contratación y dan claridad en materia impositiva.

4.2.5. La selección de la entidad sin ánimo de lucro y de reconocida idoneidad debe hacerse por proceso competitivo como regla general

A partir de la reglamentación que se hace de la figura en el Decreto 092 de 2017 y que entró en vigencia el 1. ${ }^{\circ}$ de junio del mismo año, se dispone que la regla general para la selección de la entidad con la que debe asociarse la entidad estatal es a través de un proceso competitivo.A continuación cabe preguntarse qué características debe tener dicho proceso de selección para ser calificado como competitivo. Lo primero que corresponde es constatar que, por expresa disposición del artículo $5 .^{\circ}$ del decreto en cuestión, el proceso descrito en el artículo $4 .^{\circ}$ no es vinculante ni obligatorio para los convenios de asociación del

74 Rodríguez Tamayo. Contratación pública con entidades sin ánimo de lucro, cit., 81. 
artículo 96 de la Ley 489 de $1998^{[75]}$. Lo anterior no obsta para que la entidad estatal que así lo considere pueda utilizar este como referente para el diseño del procedimiento en cuestión, adicionando o suprimiendo aspectos que atiendan a las particularidades del convenio a celebrarse, pero manteniendo el carácter abierto, público y competitivo que permita la comparación y selección objetiva de la oferta más conveniente para el desarrollo del mismo.

Así las cosas, el presupuesto para dicho proceso deberá ser la constatación durante la fase de planeación contractual de la existencia de más de una entidad sin ánimo de lucro y de reconocida idoneidad que pueda ofrecer el programa o actividad. De ello se deberá dejar constancia en los estudios y documentos previos. En caso de no ser así, podrá procederse a la contratación directa con la única entidad identificada ${ }^{76}$. En caso de existir pluralidad de posibles oferentes, podrá darse inicio a un proceso con las siguientes fases: (i) definición y publicación de los indicadores, que pueden referirse a experiencia, eficacia, eficiencia, economía, manejo del riesgo y los criterios de ponderación entre las ofertas; (ii) plazo razonable para presentar ofertas, y (iii) evaluación de las mismas, atendiendo a los criterios definidos.

Señala a continuación el artículo 5. del Decreto 092 de 2017 que dicho procedimiento podrá obviarse y contratarse directamente cuando una de las entidades sin ánimo de lucro y de reconocida idoneidad comprometa recursos para la ejecución de esas actividades en una proporción igual o mayor al 30 $\%$ del valor total del convenio a celebrarse. Sobre la naturaleza de dichos aportes, valga destacar que (i) deben ser en dinero (se pueden hacer aportes en especie, pero estos no se tienen en cuenta para el cálculo del porcentaje mínimo exigido en la norma) $)^{77}$ y (ii) los recursos aportados pueden ser propios de la entidad o provenientes de cooperación únicamente internacional. En el caso de que más de una entidad privada ofrezca su compromiso de recursos en dinero en una proporción no inferior al $30 \%$ del valor total del convenio, la norma citada prevé que la entidad estatal deberá seleccionar de forma objetiva a tal entidad y justificar los criterios para tal selección. Para ello bien podrá iniciarse un procedimiento competitivo como el ya señalado, o al menos comparar las ofertas presentadas, descartando cualquier valoración subjetiva o favoritismo, seleccionando y dejando constancia de los criterios utilizados para ello. Dentro de dicho procedimiento competitivo o de comparación nada obsta para que el aporte de recursos en especie pueda ser considerado como un criterio de ponderación o selección entre las ofertas presentadas.

75 Colombia Compra Eficiente. Circular Externa Única, cit., 70.

76 Ibíd., 71.

77 "El artículo 5 del Decreto 092 de 2017 no prohíbe la celebración de convenios en que la ESAL aporte menos del $30 \%$ o cuando aporte recursos en especie, sólo indica que en esos casos la Entidad Estatal debe acudir al proceso competitivo para seleccionar a la entidad sin ánimo de lucro con la cual celebrará el respectivo convenio". Colombia Compra Eficiente. Guía, cit., 23. 
Por último, en relación con la posibilidad de aplicar la excepción al proceso competitivo prevista en el inciso final del artículo 4. ${ }^{\circ}$ del Decreto 092 de 2017 a los convenios de asociación, a saber, cuando se trate de actividades artísticas, culturales, deportivas o de promoción de la diversidad étnica que solo pueden desarrollar determinadas personas naturales o jurídicas, contrario a lo que sostiene la Guía de Colombia Compra Eficiente ${ }^{78}$, consideramos que esta no le es aplicable por expresa disposición del inciso final del artículo $5 .^{\circ}$ del mismo decreto que señala que este artículo no rige para los convenios de asociación.

\subsubsection{Le aplican las prohibiciones, inhabilidades e incompatibilidades de la contratación estatal}

Junto con lo anterior, en virtud del artículo 5..$^{\circ}$ del Decreto 092 de 2017, a los convenios de asociación les son exigibles las prohibiciones, inhabilidades e incompatibilidades establecidas en la Constitución y en las leyes 80 de 1993, 1150 de 2007 y 1474 de 2011, en las normas que las modifiquen, aclaren, adicionen o sustituyan, o en cualquier otra norma especial. Valga la pena recordar en este punto que el convenio celebrado que vulnere dichas prohibiciones estará viciado de nulidad absoluta, sin perjuicio de las responsabilidades disciplinarias y penales que pueden derivarse de ello.

Al respecto, conviene destacar la inhabilidad prevista en el literal d del numeral 2 del artículo 8. de la Ley 80 de 1993, según el cual no podrán celebrar contratos con la entidad respectiva las corporaciones, asociaciones, fundaciones y las sociedades anónimas que no tenga el carácter de abiertas, así como las sociedades de responsabilidad limitada en las que el servidor público en los niveles directivo, asesor o ejecutivo, o miembro de la junta o consejo directivo, o el cónyuge o compañero o compañera permanente o los parientes hasta el segundo grado de consanguinidad, afinidad o civil de cualquiera de ellos, tenga participación o desempeñe cargos de dirección o manejo. Al respecto debe señalarse igualmente que dicha inhabilidad está exceptuada para las personas jurídicas sin ánimo de lucro cuyos representantes legales hagan parte de las juntas o consejos directivos en virtud de su cargo, según lo dispuesto en el parágrafo $1 .^{\circ}$ del artículo mencionado.

\subsubsection{Les aplican los principios de la contratación estatal y algunas normas presupuestales}

A la luz del artículo 7. ${ }^{\circ}$ del Decreto 092 de 2017, los convenios de asociación están sujetos a los principios de la contratación estatal y a las normas presupuestales aplicables. Respecto de estas últimas se hace referencia a lo 
dispuesto por el Decreto Ley 111 de 1996, y demás normas concordantes. En cuanto a los principios de la contratación, al no hacerse ninguna otra precisión al respecto, esto significa que son obligatorios tanto los de orden constitucional como los de orden legal. Entre los primeros pueden mencionarse, a título enunciativo, los principios de legalidad y debido proceso, al igual que los establecidos en los artículos 209 y 267 constitucionales. Entre ellos conviene destacar los de igualdad, moralidad, eficacia, economía, celeridad, imparcialidad, eficacia, equidad y publicidad $^{79}$.

En cuando a este último principio, dispone expresamente el decreto que la actividad contractual y los documentos relacionados de los convenios solidarios deberán ser objeto de publicación en el Sistema Electrónico de Contratación Pública (SECOP). Adicionalmente, la entidad privada sin ánimo de lucro contratista debe entregar a la entidad estatal, y esta publicar en el SECOP, la información a los subcontratos que suscriba para desarrollar el programa o actividad de interés público previsto en el plan de desarrollo correspondiente, incluyendo los datos referentes a la existencia y representación legal de la entidad con quien contrató y la información de desembolsos. En cuanto a los principios legales, se hace referencia a los dispuestos en las leyes 80 de 1993 y 1150 de 2007 y que sean compatibles con el régimen acá descrito, a saber, principios como los de transparencia, responsabilidad, buena fe y selección objetiva.

\subsubsection{Deben observar las normas generales del sistema de contratación pública}

Por último, en virtud de lo dispuesto por el artículo 8. del Decreto 092 de 2017 , los convenios de asociación están sujetos a las normas generales aplicables a la contratación pública, establecidas en el EGCAP y demás normas concordantes, excepto en lo reglamentado en el mencionado decreto. Como se expuso, dicha disposición supone un cambio en la regulación de estos convenios. Con fundamento en el régimen anterior, la Sección Tercera del Consejo de Estado había sostenido que, ante el silencio normativo, dada la especialidad del régimen aplicable y el interés del constituyente en que dicho régimen lo estableciera exclusivamente el Gobierno Nacional, dichos convenios de asociación no se regían por las normas generales establecidas en el EGCAP y, por ende, no requerían, a manera de ejemplo, de liquidación una vez concluida la fase de ejecución del mismo ${ }^{80}$. Ahora, una vez entrado en vigencia el Decreto

79 Sobre el significado y el alcance de los mencionados principios, véase Consejo de Estado, Sala de lo Contencioso Administrativo, Sección Tercera, Subsección C. Sentencia del 3 de diciembre de 2007. C.P.: Ruth Stella Correa Palacio. Exp. 31447.

80 Consejo de Estado, Sala de lo Contencioso Administrativo, Sección Tercera, Subsección C. Sentencia del 3 de diciembre de 2014. C.P.: Olga Mélida Valle de De la Hoz. Rad. 25000-2336-000-2014-00199-01(51832). 
092 de 2017 y en virtud de lo dispuesto en el artículo $8 .^{\circ}$, dichos convenios no solo deben ser liquidados, sino que también les son aplicables las normas relativas a estudios y documentos previos, pagos anticipados, anticipos, adiciones, supervisión y/o interventoría, análisis de riesgos y garantías, entre otras.

\section{CONCLUSIONES}

El artículo 355 constitucional consagró la prohibición expresa para todas las ramas del poder público de otorgar auxilios o donaciones a personas naturales o jurídica de derecho privado por razones de mera liberalidad, los cuales habían estado ejemplificados en los denominados "auxilios parlamentarios". Sin embargo, al mismo tiempo, dicha norma facultó a los gobiernos Nacional, departamentales y municipales para celebrar ciertos contratos con personas jurídicas privadas sin ánimo de lucro y de reconocida idoneidad cuando estos tuvieran como fin impulsar programas y actividades de interés público acordes con los planes de desarrollo correspondientes. La potestad para regular dichos convenios fue conferida expresamente al Gobierno Nacional por parte del constituyente.

Con fundamento en dicha potestad reglamentaria especial, el Gobierno expidió el Decreto 777 de 1992, modificado por los decretos 1403 de 1992 y 2459 de 1993. Estos reglamentos constitucionales o autónomos establecieron un régimen que se caracterizó por someter estos convenios al derecho privado y por excluir de dicha regulación a las relaciones conmutativas, entre otros aspectos. Posteriormente, el legislador expidió la Ley 489 de 1998, cuyo artículo 96 reguló los denominados convenios de asociación, determinando que estos podrían celebrarse por cualquier entidad estatal, que debían someterse a lo dispuesto al artículo 355 de la Constitución, y otros elementos esenciales. A pesar de los reparos de constitucionalidad que pueden hacerse a dicha norma, se generó con ella una profunda discusión sobre si estos convenios de asociación se distinguían de los regulados por el Decreto 777 de 1992 o si constituían una reiteración de dicha figura. La doctrina y la jurisprudencia se fueron inclinando por la última posición.

A raíz de algunos escándalos de corrupción y abusos de la figura, el Gobierno Nacional expidió el Decreto 092 de 2017, derogando el Decreto 777 de 1992 y demás normas concordantes. Esta nueva regulación distingue entre los convenios de asociación, creados por la Ley 489 de 1998 y reglamentados por una parte del mencionado decreto, y los convenios de interés público, que pueden celebrarse con fundamento en el segundo inciso del artículo 355 constitucional y se rigen por la totalidad de los artículos que componen el Decreto 092 de 2017 (salvo lo previsto en el artículo 5. .). En cuanto a las principales similitudes entre ambas figuras, valga destacar que: (i) ambos convenios deben celebrarse con personas jurídicas privadas sin ánimo de lucro y de reconocida idoneidad, (ii) no pueden implicar una relación con- 
mutativa entre las partes, (iii) están sometidos al régimen de inhabilidades e incompatibilidades del EGCAP, (iv) les aplican los principios de la contratación estatal y (v) están sujetos a las normas generales aplicables a la contratación pública, excepto en lo reglamentado en el Decreto 092 de 2017. En cuanto a las principales diferencias identificadas, se sintetizan en la tabla 3.

TABLA 3. DIFERENCIAS ENTRE CONVENIOS DE ASOCIACIÓN Y DE INTERÉS PÚBLICO

\begin{tabular}{|c|c|c|}
\hline & CONVENIO DE ASOCIACIÓN & CONVENIO DE INTERÉS PÚBLICO \\
\hline FINALIDAD & No conmutativa & Benéfica o de auxilio \\
\hline ОвЈето & $\begin{array}{l}\text { Desarrollo conjunto de } \\
\text { actividades relacionadas con } \\
\text { los cometidos y funciones } \\
\text { asignadas por la ley a las } \\
\text { entidades estatales. }\end{array}$ & $\begin{array}{l}\text { Ejecución de programas o actividades } \\
\text { acordes con los planes nacional y } \\
\text { seccionales de desarrollo, y que con } \\
\text { ello se pretenda exclusivamente } \\
\text { promover los derechos de personas } \\
\text { en situación de debilidad manifiesta } \\
\text { o indefensión, los derechos de las } \\
\text { minorías, el derecho a la educación, el } \\
\text { derecho a la paz, las manifestaciones } \\
\text { artísticas, culturales, deportivas y de } \\
\text { promoción de la diversidad étnica } \\
\text { colombiana. }\end{array}$ \\
\hline ENTIDAD CONTRATANTE & $\begin{array}{l}\text { Entidad estatal, cualquiera } \\
\text { sea su naturaleza y orden } \\
\text { administrativo. }\end{array}$ & $\begin{array}{l}\text { Exclusivamente entidades que } \\
\text { pertenezcan a la rama ejecutiva del } \\
\text { nivel nacional o descentralizado } \\
\text { territorialmente y por servicios. }\end{array}$ \\
\hline APORTE EN DINERO & $\begin{array}{l}\text { Requerido por todas las partes } \\
\text { contratantes. }\end{array}$ & $\begin{array}{l}\text { Puede ser únicamente por la entidad } \\
\text { contratante. }\end{array}$ \\
\hline $\begin{array}{l}\text { AUTORIZACIÓN POR PARTE } \\
\text { DEL REPRESENTANTE LEGAL } \\
\text { DE LA ENTIDAD ESTATAL }\end{array}$ & $\begin{array}{l}\text { No es requerida y, por tanto, su } \\
\text { autorización se podrá delegar. }\end{array}$ & Es requerida y no se podrá delegar. \\
\hline $\begin{array}{l}\text { PROCEDIMIENTO DE } \\
\text { SELECCIÓN }\end{array}$ & $\begin{array}{l}\text { Por regla general, se debe } \\
\text { surtir un procedimiento } \\
\text { competitivo, salvo cuando la } \\
\text { entidad sin ánimo de lucro } \\
\text { comprometa recursos en dinero } \\
\text { en una proporción no inferior } \\
\text { al } 30 \% \text { del valor total del } \\
\text { convenio o sea la única que } \\
\text { pueda proveer dicha actividad } \\
\text { o servicio. }\end{array}$ & $\begin{array}{l}\text { Por regla general, se debe surtir un } \\
\text { procedimiento competitivo, siempre } \\
\text { y cuando no existan otras entidades } \\
\text { privadas sin ánimo de lucro y de } \\
\text { reconocida idoneidad que ofrezcan los } \\
\text { bienes, obras o servicios requeridos. } \\
\text { Sin embargo, el proceso competitivo } \\
\text { no resultará obligatorio cuando el } \\
\text { objeto del proceso "corresponde a } \\
\text { actividades artísticas, culturales, } \\
\text { deportivas y de promoción de la } \\
\text { diversidad étnica colombiana, que } \\
\text { solo pueden desarrollar determinadas } \\
\text { personas naturales o jurídicas". }\end{array}$ \\
\hline
\end{tabular}

Fuente: elaboración propia. 
Como se evidencia, el Decreto 092 de 2017 supone un cambio significativo a la regulación que se hacía del artículo 355 superior y del artículo 96 de la Ley 489 de 1998, por lo cual su interpretación y aplicación comporta importantes retos para los operadores jurídicos. Estas inquietudes solo se irán disipando con la consolidación de la doctrina y la jurisprudencia al respecto. Mientras ello sucede, y con la pretensión de contribuir a la labor diaria y dispendiosa en la materia, se construyó este artículo, haciendo siempre énfasis en que con las modalidades contractuales allí reguladas nunca se debe perder de vista su carácter excepcional y benéfico, que encuentra plena justificación en el desarrollo de los fines que le son inherentes al Estado social de derecho, y nunca servir de vehículo para la corrupción administrativa.

\section{REFERENCIAS}

\section{Doctrina}

Cabanellas, G. Diccionario Enciclopédico de Derecho Usual. T. iI. Buenos Aires: Heliasta, 1997.

Chávez Marín, A. R. Los convenios de la Administración. Entre la gestión pública y la actividad contractual. 3. . ed. Bogotá: Temis, 2015.

Dávila Vinueza, L. G. Régimen jurídico de la contratación estatal.3. a ed. Bogotá: Temis, 2016.

Escola, H. J. El interés público como fundamento del derecho administrativo. Buenos Aires: Depalma, 1989.

Fonseca Gómez, Ó. J. Los convenios de asociación. Una mirada desde el estatuto contractual y el Distrito Capital. Tesis de maestría en Derecho. Bogotá: Universidad Nacional de Colombia, 2012.

Lucas Pachón, C. Contratación pública. Análisis normativo, descripción de procedimientos. Bogotá: ECOE, 2014.

Naranjo Cely, V. A. Los convenios de asociación e interés público, entre el ejercicio del poder discrecional de la Administración y la aplicación de los principios de la contratación estatal en Colombia. Tesis maestría en Derecho. Bogotá: Universidad Nacional de Colombia, 2014.

Ospina Fernández, G. y Ospina Acosta, E. Teoría general del contrato y del negocio jurídico. 7. a ed. Bogotá: Temis, 2005.

Parada, R. Concepto y fuentes del derecho administrativo. Madrid: Marcial Pons, 2008.

Quinche Ramírez, M. F. y Urrego Ortiz, F. Los decretos presidenciales en el sistema normativo. Bogotá: Doctrina y Ley, 2011.

Restrepo Salazar, J. C. Hacienda Pública. 9. ${ }^{a}$ ed. Bogotá: Universidad Externado de Colombia, 2012. 
Rodríguez Tamayo, M. Contratación pública con entidades sin ánimo de lucro. Decreto 092 de 2017. Bogotá: Legis, 2017.

RodríGuez, L. Derecho administrativo: general y colombiano. 18. a ed. Bogotá: Temis, 2013.

Santos Rodríguez, J. E. Consideración sobre los contratos y convenios interadministrativos. En Revista digital de Derecho Administrativo, Universidad Externado de Colombia. N. $1,2009$.

Vidal Perdomo, J. Derecho administrativo. 14. a ed. Bogotá: Legis, 2016.

\section{Normatividad}

Alcaldía de Medellín. Decreto Municipal n. 1920 del 1. ${ }^{\circ}$ de diciembre de 2015.

Alcaldía Mayor de Bogotá. Decreto Distrital n. ${ }^{\circ} 153$ de 2010.

Colombia Compra Eficiente. Circular Externa Única. Disponible en: https://www.colombiacompra.gov.co/sites/cce_public/files/cce_circulares/cce_circular_unica.pdf.

Colombia Compra Eficiente. Guía para la contratación con entidades sin ánimo de lucro y de reconocida idoneidad. 24 de abril de 2017. Disponible en: https://www.colombiacompra.gov.co/tags/guia-para-la-contratacion-con-entidades-sin-animo-de-lucroy-de-reconocida-idoneidad.

Decreto 092 de 2017 del Departamento Nacional de Planeación, "Por medio del cual se reglamenta la contratación con entidades privadas sin ánimo de lucro a la que hace referencia el inciso segundo del artículo 355 de la Constitución Política", del 23 de enero de 2017

Decreto 777 de 1992, "Por el cual se reglamenta la celebración de los contratos a que refiere el inciso segundo del artículo 355 de la Constitución Política”, del 16 de mayo de 1992.

Dian, Subdirección de Gestión Normativa y Doctrina. Oficio n. ${ }^{\circ} 006354$ del 27 de febrero de 2015. 100208221-000300. Rad. 002030 del 21 de enero de 2015.

Gobernación de Antioquia. Circular n. ${ }^{\circ} 000386$ del 19 de septiembre de 2012.

Ley 489 de 1998, "Por la cual se dictan normas sobre la organización y funcionamiento de las entidades del orden nacional, se expiden las disposiciones, principios y reglas generales para el ejercicio de las atribuciones previstas en los numerales 15 y 16 del artículo 189 de la Constitución Política y se dictan otras disposiciones", del 29 de diciembre de 1998. DO n. 43464.

\section{Jurisprudencia}

Consejo de Estado, Sala de Consulta y Servicio Civil. Concepto 1710 del 23 de febrero de 2006. C.P.: Luis Fernando Álvarez Jaramillo.

Consejo de Estado, Sala de Consulta y Servicio Civil. Concepto 1957 del 3 de septiembre de 2009. C.P.: Enrique José Arboleda Perdomo. 
Consejo de Estado, Sala de Consulta y Servicio Civil. Concepto 2146 del 12 de septiembre de 2013. C.P.: William Zambrano Cetina.

Consejo de Estado, Sala de lo Contencioso Administrativo, Sección Tercera. Auto del 5 de julio de 2017. C.P.: Jaime Orlando Santofimio Gamboa. Actor: Julián Andrés Cotes Buitrago y otros. Demandado: Departamento Nacional de Planeación. Rad. 11100103-26-000-2017-00083-00 (59493).

Consejo de Estado, Sala de lo Contencioso Administrativo, Sección Tercera. Subsección C. Sentencia del 3 de diciembre de 2007. C.P.: Ruth Stella Correa Palacio. Exp. 31447.

Consejo de Estado, Sala de lo Contencioso Administrativo, Sección Tercera. Sentencia del 14 de agosto de 2008. C.P.: Mauricio Fajardo Gómez. Rad. 11001032600019990 001201(16230).

Consejo de Estado, Sala de lo Contencioso Administrativo, Sección Tercera. Sentencia del 14 de mayo de 2014. C.P.: Mauricio Fajardo Gómez. Rad. 1100110326000201400035 00(50222). Actor: Martín Bermúdez Muñoz. Demandado: Departamento Nacional de Planeación.

Consejo de Estado, Sección Tercera, Subsección A. Sentencia del 13 de agosto de 2014. C.P.: Carlos Alberto Zambrano Barrera. Actor: Gloria Lyda Rengifo Alarcón. Demandado. Municipio de Palmira y otros. Rad. 76001-23-31-000-2000-01885-01 (26765).

Consejo de Estado, Sala de lo Contencioso Administrativo, Sección Tercera, Subsección B. Sentencia del 5 de diciembre de 2016. C.P.: Ramiro Pazos Guerrero. Exp. 41333. Rad. 05001233100020030366301.

Consejo de Estado, Sala de lo Contencioso Administrativo, Sección Tercera, Subsección C. Sentencia del 23 de mayo de 2012. C.P.: Olga Mélida Valle de De La Hoz. Actor: Luis Nelson Fontalvo Prieto. Demandado: Ministerio de Agricultura y Desarrollo Rural. Rad. 25000-23-26-000-1998-01471-01(22828).

Consejo de Estado, Sala de lo Contencioso Administrativo, Sección Tercera, Subsección C. Sentencia del 3 de diciembre de 2014. C.P.: Olga Mélida Valle de De La Hoz. Actor: Asociación Promotora de Proyectos Servicios y Asesoría Culturales Proactiva y otros. Demandado: Bogotá - Distrito Capital - Secretaría Distrital de Integración Social. Rad. 25000-23-36-000-2014-00199-01(51832).

Corte Constitucional, Sala Plena. Sentencia C-337 de 1993. M.P.: Vladimiro Naranjo Mesa.

Corte Constitucional, Sala Plena. Sentencia C-372 de 1994. M.P.: Vladimiro Naranjo Mesa.

Corte Constitucional, Sala Plena. Sentencia C-506 de 1994. M.P.: Fabio Morón Díaz.

Corte Constitucional, Sala Plena. Sentencia C-205 de 1995. M.P.: Eduardo Cifuentes Muñoz.

Corte Constitucional, Sala Plena. Sentencia C-254 de 1996. M.P.: Eduardo Cifuentes Muñoz.

Corte Constitucional, Sala Plena. Sentencia C-152 de 1999. M.P.: Eduardo Cifuentes Muñoz.

Corte Constitucional, Sala Plena. Sentencia C-671 de 1999. M.P.: Alfredo Beltrán Sierra.

Corte Constitucional, Sala Plena. Sentencia C-922 de 2000. M.P.: Antonio Barrera Carbonell. 
Corte Constitucional, Sala Plena. Sentencia C-543 de 2001. M.P.: Álvaro Tafur Galvis.

Corte Constitucional, Sala Plena. Sentencia C-651 de 2001. M.P.: Alfredo Beltrán Sierra.

Corte Constitucional, Sala Plena. Sentencia C-1168 de 2001. M.P.: Eduardo Montealegre Lynett.

Corte Constitucional, Sala Plena. Sentencia C-1174 de 2001. M.P.: Clara Inés Vargas Hernández.

Corte Constitucional, Sala Plena. Sentencia C-1250 de 2001. M.P.: Manuel José Cepeda Espinosa.

Corte Constitucional, Sala Plena. Sentencia C-1290 de 2001. M.P.: Álvaro Tafur Galvis.

Corte Constitucional, Sala Plena. Sentencia C-712 de 2002. M.P.: Álvaro Tafur Galvis.

Corte Constitucional, Sala Plena. Sentencia C-130 de 2003. M.P.: Rodrigo Escobar Gil.

Corte Constitucional, Sala Plena. Sentencia C-022 de 2004. M.P.: Alfredo Beltrán Sierra.

Corte Constitucional, Sala Plena. Sentencia C-507 de 2008. M.P.: Jaime Córdoba Triviño.

Corte Constitucional, Sala Plena. Sentencia C-324 de 2009. M.P.: Juan Carlos Henao Pérez.

Corte Constitucional, Sala Plena. Sentencia C-044 de 2015. M.P.: María Victoria Calle Correa.

Corte Constitucional, Sala Plena. Sentencia C-027 de 2016. M.P.: María Victoria Calle Correa.

Corte Suprema de Justicia, Sala Penal. Sentencia del 25 de enero de 2017. M.P.: Patricia Salazar Cuéllar. Proceso 48.250. 